\title{
A regional carbon data assimilation system and its preliminary evaluation in East Asia
}

\author{
Z. Peng ${ }^{1}$, M. Zhang ${ }^{2}$, X. Kou ${ }^{2,3}$, X. Tian ${ }^{4}$, and X. Ma ${ }^{4}$ \\ ${ }^{1}$ School of Atmospheric Sciences, Nanjing University, Nanjing 210093, China \\ ${ }^{2}$ State Key Laboratory of Atmospheric Boundary Layer Physics and Atmospheric Chemistry, Institute of Atmospheric \\ Physics, Chinese Academy of Sciences, Beijing 100029, China \\ ${ }^{3}$ Graduate School of Chinese Academy of Sciences, University of Chinese Academy of Sciences, Beijing 100049, China \\ ${ }^{4}$ Institute of Atmospheric Physics, Chinese Academy of Sciences, Beijing 100029, China
}

Correspondence to: Z. Peng (pengzhen@nju.edu.cn) and M. Zhang (mgzhang@mail.iap.ac.cn)

Received: 21 June 2014 - Published in Atmos. Chem. Phys. Discuss.: 8 August 2014

Revised: 15 November 2014 - Accepted: 29 December 2014 - Published: 30 January 2015

\begin{abstract}
In order to optimize surface $\mathrm{CO}_{2}$ fluxes at grid scales, a regional surface $\mathrm{CO}_{2}$ flux inversion system (Carbon Flux Inversion system and Community Multi-scale Air Quality, CFI-CMAQ) has been developed by applying the ensemble Kalman filter (EnKF) to constrain the $\mathrm{CO}_{2}$ concentrations and applying the ensemble Kalman smoother (EnKS) to optimize the surface $\mathrm{CO}_{2}$ fluxes. The smoothing operator is associated with the atmospheric transport model to constitute a persistence dynamical model to forecast the surface $\mathrm{CO}_{2}$ flux scaling factors. In this implementation, the "signalto-noise" problem can be avoided; plus, any useful observed information achieved by the current assimilation cycle can be transferred into the next assimilation cycle. Thus, the surface $\mathrm{CO}_{2}$ fluxes can be optimized as a whole at the grid scale in CFI-CMAQ. The performance of CFI-CMAQ was quantitatively evaluated through a set of Observing System Simulation Experiments (OSSEs) by assimilating $\mathrm{CO}_{2}$ retrievals from GOSAT (Greenhouse Gases Observing Satellite). The results showed that the $\mathrm{CO}_{2}$ concentration assimilation using EnKF could constrain the $\mathrm{CO}_{2}$ concentration effectively, illustrating that the simultaneous assimilation of $\mathrm{CO}_{2}$ concentrations can provide convincing $\mathrm{CO}_{2}$ initial analysis fields for $\mathrm{CO}_{2}$ flux inversion. In addition, the $\mathrm{CO}_{2}$ flux optimization using EnKS demonstrated that CFI-CMAQ could, in general, reproduce true fluxes at grid scales with acceptable bias. Two further sets of numerical experiments were conducted to investigate the sensitivities of the inflation factor of scaling factors and the smoother window. The results showed that the ability of CFI-CMAQ to optimize $\mathrm{CO}_{2}$ fluxes greatly relied
\end{abstract}

on the choice of the inflation factor. However, the smoother window had a slight influence on the optimized results. CFICMAQ performed very well even with a short lag-window (e.g. 3 days).

\section{Introduction}

Considerable progress has been made in recent years to reduce the uncertainties of surface $\mathrm{CO}_{2}$ flux estimates through the use of an advanced data assimilation technique (e.g. Chevallier, 2007; Chevallier et al., 2005, 2007; Baker et al., 2006; Engelen et al., 2009; Liu et al., 2012). Feng et al. (2009) showed that the uncertainties of surface $\mathrm{CO}_{2}$ flux estimates can be reduced significantly by assimilating OCO $\mathrm{X}_{\mathrm{CO}_{2}}$ measurements. Peters et al. $(2005,2007,2009)$ developed a surface $\mathrm{CO}_{2}$ flux inversion system, CarbonTracker, by incorporating the ensemble square-root filter (EnSRF) into the atmospheric transport TM5 model; the inversion results obtained by assimilating in situ surface $\mathrm{CO}_{2}$ observations are in excellent agreement with a wide collection of carbon inventories that form the basis of the first North American State of the Carbon Cycle Report (SOCCR) (Peters et al., 2007). CarbonTracker has also been frequently used to constrain the surface $\mathrm{CO}_{2}$ fluxes over Europe and Asia (eg., Zhang et al., 2014a, b). Kang et al. (2012) presented a simultaneous data assimilation of surface $\mathrm{CO}_{2}$ fluxes and atmospheric $\mathrm{CO}_{2}$ concentrations along with meteorological variables using a local ensemble transform Kalman filter (LETKF). They indicated 
that an accurate estimation of the evolving surface fluxes can be gained even without any a priori information. Recently, Tian et al. (2014) developed a new surface $\mathrm{CO}_{2}$ flux data assimilation system, Tan-Tracker, by incorporating a joint PODEn4DVar assimilation framework into the GEOS-Chem model on the basis of Peters et al. $(2005,2007)$ and Kang et al. $(2011,2012)$. They discussed in detail that the assimilation of $\mathrm{CO}_{2}$ surface fluxes could be improved through the use of simultaneous assimilation of $\mathrm{CO}_{2}$ concentrations and $\mathrm{CO}_{2}$ surface fluxes. Despite the rigour of data assimilation theory, current $\mathrm{CO}_{2}$ flux-inversion methods still face many challenging scientific problems, such as: (1) the well-known "signal-to-noise" problem (NRC, 2010); (2) large inaccuracies in chemical transport models (e.g. Prather et al., 2008); (3) vast computational expenses (e.g. Feng et al., 2009); and (4) the sparseness of observation data (e.g. Gurney et al., 2002).

The "signal-to-noise" problem is one of the most challenging issues for an ensemble-based $\mathrm{CO}_{2}$ flux inversion system due to the fact that surface $\mathrm{CO}_{2}$ fluxes are the model forcing (or boundary condition), rather than model states (like $\mathrm{CO}_{2}$ concentrations), of the chemistry transport model (CTM). In the absence of a suitable dynamical model to describe the evolution of the surface $\mathrm{CO}_{2}$ fluxes, most $\mathrm{CO}_{2}$ flux-inversion studies have traditionally ignored the uncertainty of anthropogenic and other $\mathrm{CO}_{2}$ emissions and focused on the optimization of natural (i.e. biospheric and oceanic) $\mathrm{CO}_{2}$ emissions at the ecological scale (e.g. Deng et al., 2007; Feng et al., 2009; Peters et al., 2005, 2007; Jiang et al., 2013; Peylin et al., 2013).

This compromise is acceptable to some extent. Indeed, the total amount of anthropogenic $\mathrm{CO}_{2}$ emissions can be estimated by relatively well-documented global fuelconsumption data with a small degree of uncertainty (Boden et al., 2011), and the uncertainties involved in the total amount of anthropogenic $\mathrm{CO}_{2}$ emissions are much smaller than those related to natural emissions. However, their spatial distribution, strength and temporal development still remain elusive because of their inherent non-uniformities (Andres et al., 2012; Gurney et al., 2009). Marland (2008) pointed out that even a tiny amount of uncertainty, i.e. $0.9 \%$, in one of the leading emitter countries like the U.S. is equivalent to the total emissions of the smaller emitter countries in the world. Furthermore, the usual values of anthropogenic $\mathrm{CO}_{2}$ emissions in chemical transport models have thus far been simply interpolated from very coarse monthly-mean fuel consumption data. Therefore, great uncertainty in the spatiotemporal distributions of anthropogenic emissions likely exists, which could reduce the accuracy of $\mathrm{CO}_{2}$ concentration simulations and subsequently increase the inaccuracy of natural $\mathrm{CO}_{2}$ flux inversion results. In addition, current research approaches tend only to assimilate natural $\mathrm{CO}_{2}$ emissions at the ecological scale, which is far from sufficient. Therefore, surface $\mathrm{CO}_{2}$ fluxes should be constrained as a whole at a finer scale.
In CarbonTracker (Peters at al., 2007), a smoothing operator is innovatively applied as the persistence forecast model. In that application, the surface $\mathrm{CO}_{2}$ fluxes can be treated as the model states and the observed information ingested by the current assimilation cycle can be used in the next assimilation cycle effectively. However, the "signal-to-noise" problem has not yet been resolved, and thus CarbonTracker also has to assimilate natural $\mathrm{CO}_{2}$ emissions at the ecological scale only. In Tan-Tracker (Tian et al., 2014), a fourdimensional (4-D) moving sampling strategy (Wang et al., 2010) is used to generate the flux ensemble members, and so the surface $\mathrm{CO}_{2}$ fluxes can be optimized as a whole at the grid scale. In this work, the persistence dynamical model taken by Peters et al. (2005) was further developed for the purpose of resolving the "signal-to-noise" problem, to optimize the surface $\mathrm{CO}_{2}$ fluxes as a whole at the grid scale. This process is described in detail in Sect. 2 of this paper.

The surface $\mathrm{CO}_{2}$ flux inversion system presented in this paper was developed by simultaneously optimizing the surface $\mathrm{CO}_{2}$ fluxes and constraining the $\mathrm{CO}_{2}$ concentrations. As we know, assimilating $\mathrm{CO}_{2}$ observations from multiple sources can improve the accuracy of simulation results (e.g. Miyazaki, 2009; Liu et al., 2011, 2012; Feng et al., 2011; Tangborn et al., 2013; Huang et al., 2014). In addition, previous studies showed that the simultaneous assimilation of $\mathrm{CO}_{2}$ concentrations and surface $\mathrm{CO}_{2}$ fluxes can largely eliminate the uncertainty in initial $\mathrm{CO}_{2}$ concentrations on the $\mathrm{CO}_{2}$ evolution (Kang et al., 2012; Tian et al., 2014). Therefore, we also use the simultaneous assimilation framework; the ensemble Kalman filter (EnKF) was used to constrain $\mathrm{CO}_{2}$ concentrations and the ensemble Kalman smoother (EnKS) was used to optimize surface $\mathrm{CO}_{2}$ fluxes. Since the regional chemical transport models, compared to global models, have some advantages in reproducing the effects of meso-microscale transport on atmospheric $\mathrm{CO}_{2}$ distributions (Ahmadov et al., 2009; Pillai et al., 2011; Kretschmer et al., 2012), we choose a regional model, Regional Atmospheric Modeling System and Community Multi-scale Air Quality (RAMSCMAQ) (Zhang et al., 2002, 2003, 2007; Kou et al., 2013; Liu et al., 2013; Huang et al., 2014), to develop this inversion system. For simplicity, this system is referred to as CFI-CMAQ (Carbon Flux Inversion system and Community Multi-scale Air Quality).

Since this is the first introduction of CFI-CMAQ, we focus mainly on introducing the methodology in this paper. Nevertheless, in addition, Observing System Simulation Experiments (OSSEs) were designed to assess the system's ability to optimize surface $\mathrm{CO}_{2}$ fluxes. The retrieval information of GOSAT $\mathrm{X}_{\mathrm{CO}_{2}}$ are used to generate artificial observations because of the sparseness and heterogeneity of ground-based measurements.

The remainder of the paper is organized as follows. Section 2 describes the details of the regional surface $\mathrm{CO}_{2}$ flux inversion system, CFI-CMAQ, including the developed persistence dynamical model, a simple review of the EnKS and 
EnKF assimilation approaches, and the process involved. The experimental designs are then introduced and the assimilation results shown in Sect. 3. Finally, a summary and conclusions are provided in Sect. 4.

\section{Framework of the regional surface $\mathrm{CO}_{2}$ flux inversion system}

Suppose we have the prescribed net $\mathrm{CO}_{2}$ surface flux, $F^{*}(x, y, z, t)$, which can be released from a climate model or be generated by other's methods, our ultimate goal is to optimize $F^{*}(x, y, z, t)$ by assimilating $\mathrm{CO}_{2}$ observations from various platforms. As an ensemble-based assimilation system, CFI-CMAQ was also developed by applying a set of linear multiplication factors, similar to the approach by Peters et al. (2007) and Tian et al. (2014). The $i$ th ensemble member of the surface fluxes, $F_{i}(x, y, z, t)$, from an $N$-member ensemble can be described by

$F_{i}(x, y, z, t)=\lambda_{i}(x, y, z, t) F^{*}(x, y, z, t),(i=1, \ldots, N)$,

where $\lambda_{i}(x, y, z, t)$ represents the $i$ th ensemble member of the linear scaling factors (Peters et al., 2007; Tian et al., 2014) for each time and each grid to be optimized in the assimilation. The notations are standard: the subscript $i$ refers to the $i$ th ensemble member. In the following, $\lambda_{i}(x, y, z, t)$ is referred to as $\lambda_{i, t}, F^{*}(x, y, z, t)$ is referred to as $\mathbf{F}_{t}^{*}$, and $F_{i}(x, y, z, t)$ is referred to as $\mathbf{F}_{i, t}$ for simplicity.

At each optimization cycle, CFI-CMAQ includes the following four parts in turn (see Fig. 1): (1) forecasting of the linear scaling factors at time $t$, $\lambda_{i, t \mid t-1}^{\mathrm{a}}$; (2) optimization of the scaling factors in the smoother window, $\left(\lambda_{i, t-M \mid t-1}^{\mathrm{a}}, \lambda_{i, t-M+1 \mid t-1}^{\mathrm{a}}, \ldots\right.$, $\left.\lambda_{i, j \mid t-1}^{\mathrm{a}}, \ldots, \lambda_{i, t-1 \mid t-1}^{\mathrm{a}}, \lambda_{i, t \mid t-1}^{\mathrm{a}}\right), \quad$ by EnKS, where $\lambda_{i, j \mid t-1}^{\mathrm{a}}(j=t-1-M, \ldots, t-1)$ refer to analysed quantities from the previous assimilation cycle at time $j$ (see Fig. 1), $\mid t-1$ means that these factors have been updated using observations before time $t-1$, and the superscript $a$ refers to the analysed; (3) updating of the fluxes in the smoother window, $\left(\mathbf{F}_{i, t-M \mid t-1}^{\mathrm{a}}, \mathbf{F}_{i, t-M+1 \mid t-1}^{\mathrm{a}}, \ldots\right.$, $\left.\mathbf{F}_{i, j \mid t-1}^{\mathrm{a}}, \ldots, \mathbf{F}_{i, t-1 \mid t-1}^{\mathrm{a}}, \mathbf{F}_{i, t \mid t-1}^{\mathrm{a}}\right)$; and (4) assimilation of the forecast $\mathrm{CO}_{2}$ concentration fields at time $t, C_{i}^{\mathrm{f}}(x, y, z, t)$ (referred to as $\mathbf{C}_{i, t}^{\mathrm{f}}$, and the superscript $f$ refers to the forecast or the background), by EnKF. A flowchart illustrating CFI-CMAQ is presented in Fig. 2. The assimilation procedure is addressed in detail below. In addition, the observation operator is introduced, particularly for use in the GOSAT $\mathrm{X}_{\mathrm{CO}_{2}}$ data in Sect. 2.4. Furthermore, covariance inflation and localization techniques applied in CFI-CMAQ are introduced briefly in Sect. 2.5.

\subsection{Forecasting the linear scaling factors at time $t$} $\lambda_{i, t \mid t-1}^{\mathrm{a}}$

In the previous assimilation cycle $t-1-M \sim t-1$ (see Fig. 1), the optimized scaling factors in the smoother window are $\left(\lambda_{i, t-1-M \mid t-1}^{\mathrm{a}}, \lambda_{i, t-M \mid t-1}^{\mathrm{a}}, \lambda_{i, t-M+1 \mid t-1}^{\mathrm{a}}, \ldots\right.$, $\left.\lambda_{i, j \mid t-1}^{\mathrm{a}}, \ldots, \lambda_{i, t-1 \mid t-1}^{\mathrm{a}}\right)$ and the assimilated $\mathrm{CO}_{2}$ concentration fields at time $t-1$ are $C_{i}^{\mathrm{a}}(x, y, z, t-1)$ (referred to as $\mathbf{C}_{i, t-1}^{\mathrm{a}}$ ). In the current assimilation cycle $t-M \sim t$, the scaling factors in the current smoother window are $\left(\lambda_{i, t-M \mid t-1}^{\mathrm{a}}, \lambda_{i, t-M+1 \mid t-1}^{\mathrm{a}}, \ldots, \lambda_{i, j \mid t-1}^{\mathrm{a}}, \ldots\right.$, $\left.\lambda_{i, t-1 \mid t-1}^{\mathrm{a}}, \lambda_{i, t \mid t-1}^{\mathrm{a}}\right)$ and the forecast $\mathrm{CO}_{2}$ concentration fields at time $t$ are $\mathbf{C}_{i, t}^{\mathrm{f}}$.

In order to pass the useful observed information onto the next assimilation cycle effectively, following Peters et al. (2007) the smoothing operator is applied as part of the persistence dynamical model to calculate the linear scaling factors $\lambda_{i, t \mid t-1}^{\mathrm{a}}$,

$\lambda_{i, t \mid t-1}^{\mathrm{a}}=\frac{\left(\sum_{j=t-M}^{t-1} \lambda_{i, j \mid t-1}^{\mathrm{a}}+\lambda_{i, t \mid t-1}^{\mathrm{p}}\right)}{M+1},(i=1, \ldots, N)$,

where $\lambda_{i, t \mid t-1}^{\mathrm{p}}$ refers to the prior values of the linear scaling factors at time $t$. The superscript $p$ refers to the prior. This operation represents a smoothing over all the time steps in the smoother window (see Fig. 1), thus dampening variations in the forecast of $\lambda_{i, t \mid t-1}^{\mathrm{a}}$ in time.

In order to generate $\lambda_{i, t \mid t-1}^{\mathrm{p}}$, the atmospheric transport model (CMAQ) is applied and a set of ensemble forecast experiments are carried out. It integrates from time $t-1$ to $t$ to produce the $\mathrm{CO}_{2}$ concentration fields $\hat{C}_{i}^{\mathrm{f}}(x, y, z, t)$ (referred to as $\hat{C}_{i, t}^{\mathrm{f}}$ hereafter to distinguish from $\mathbf{C}_{i, t}^{\mathrm{f}}$ ) forced by the prescribed net $\mathrm{CO}_{2}$ surface flux $\mathbf{F}_{t}^{*}$ with $\mathbf{C}_{i, t-1}^{a}$ as initial conditions. Then, the ratio $\kappa_{i, t}=\hat{C}_{i, t}^{\mathrm{f}} / \overline{\hat{C}_{i, t}^{\mathrm{f}}}$ is calculated, where $\overline{\hat{C}_{i, t}^{\mathrm{f}}}=\frac{1}{N} \sum_{i=1}^{N} \hat{C}_{i, t}^{\mathrm{f}}$. Suppose that $\lambda_{i, t \mid t-1}^{\mathrm{p}}=\kappa_{i, t}$ due to the fact that the surface $\mathrm{CO}_{2}$ fluxes correlate with its concentrations, the values for $\lambda_{i, t \mid t-1}^{\mathrm{p}}$ are obtained and then $\lambda_{i, t \mid t-1}^{\mathrm{a}}$ can finally be calculated (see the red arrows in the flowchart in Fig. 2).

The way the prior scaling factor $\lambda_{i, t \mid t-1}^{\mathrm{p}}$ is updated by associating with the atmospheric transport model is the main improvement over the one used in CarbonTracker (Peters et al., 2007). In CarbonTracker, all $\lambda_{i, t \mid t-1}^{\mathrm{p}}$ are set to 1 (Peters et al., 2007). The distribution of the ensemble members of the linear scaling factors at time $t, \lambda_{i, t \mid t-1}^{\mathrm{p}}$, are finally dependent on the distribution of the previous scaling factors because Eq. (2) is a linear smoothing operator. In this study, the values of $\lambda_{i, t \mid t-1}^{\mathrm{p}}$ are updated by association with the atmospheric transport model. It is important to note that $\lambda_{i, t \mid t-1}^{\mathrm{p}}$ in this study are rand fields with mean 1 . However, the distribution of $\lambda_{i, t \mid t-1}^{\mathrm{a}}$ are dependent on the distribution of all 


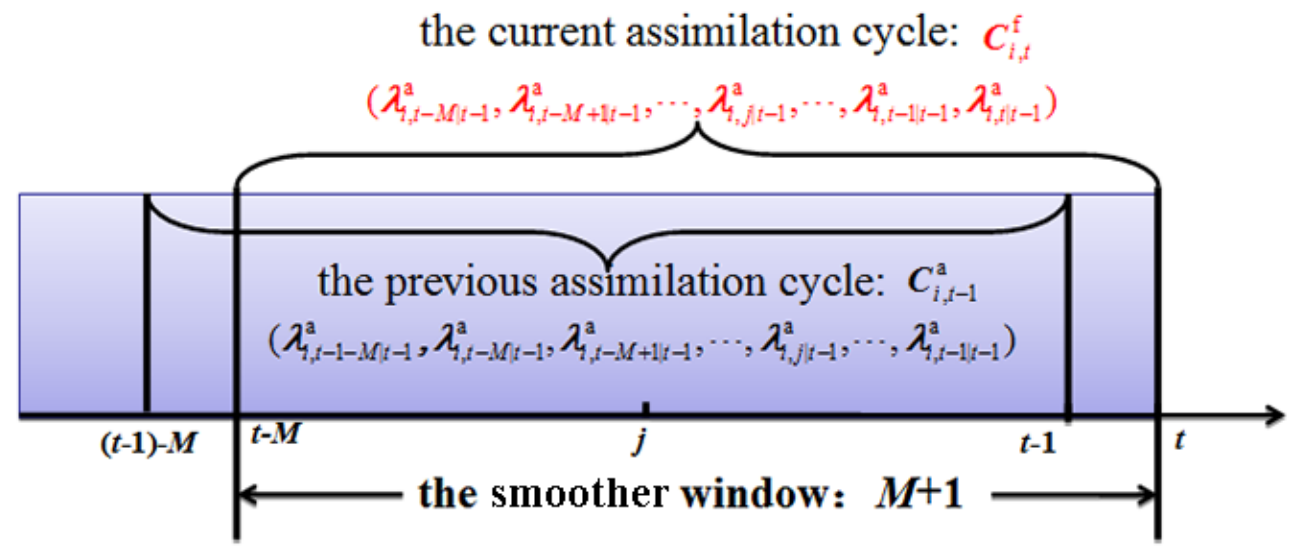

Figure 1. Schematic diagram of the smoother window. $\left(\lambda_{i, t-1-M \mid t-1}^{\mathrm{a}}, \lambda_{i, t-M \mid t-1}^{\mathrm{a}}, \lambda_{i, t-M+1 \mid t-1}^{\mathrm{a}}, \ldots, \lambda_{i, j \mid t-1}^{\mathrm{a}}, \ldots, \lambda_{i, t-1 \mid t-1}^{\mathrm{a}}\right)$ are the optimized scaling factors in the smoother window and $\mathbf{C}_{i, t-1}^{\mathrm{a}}$ are the assimilated $\mathrm{CO}_{2}$ concentrations fields at time $t-1$ in the previous assimilation cycle $t-1-M \sim t-1$. $\left(\lambda_{i, t-M \mid t-1}^{\mathrm{a}}, \lambda_{i, t-M+1 \mid t-1}^{\mathrm{a}}, \ldots, \lambda_{i, j \mid t-1}^{\mathrm{a}}, \ldots, \lambda_{i, t-1 \mid t-1}^{\mathrm{a}}, \lambda_{i, t \mid t-1}^{\mathrm{a}}\right)$ are the scaling factors in the smoother window and $\mathbf{C}_{i, t}^{\mathrm{f}}$ are the forecast $\mathrm{CO}_{2}$ concentrations fields at time $t$ which need to be optimized in the current assimilation cycle $t-M \sim t$.

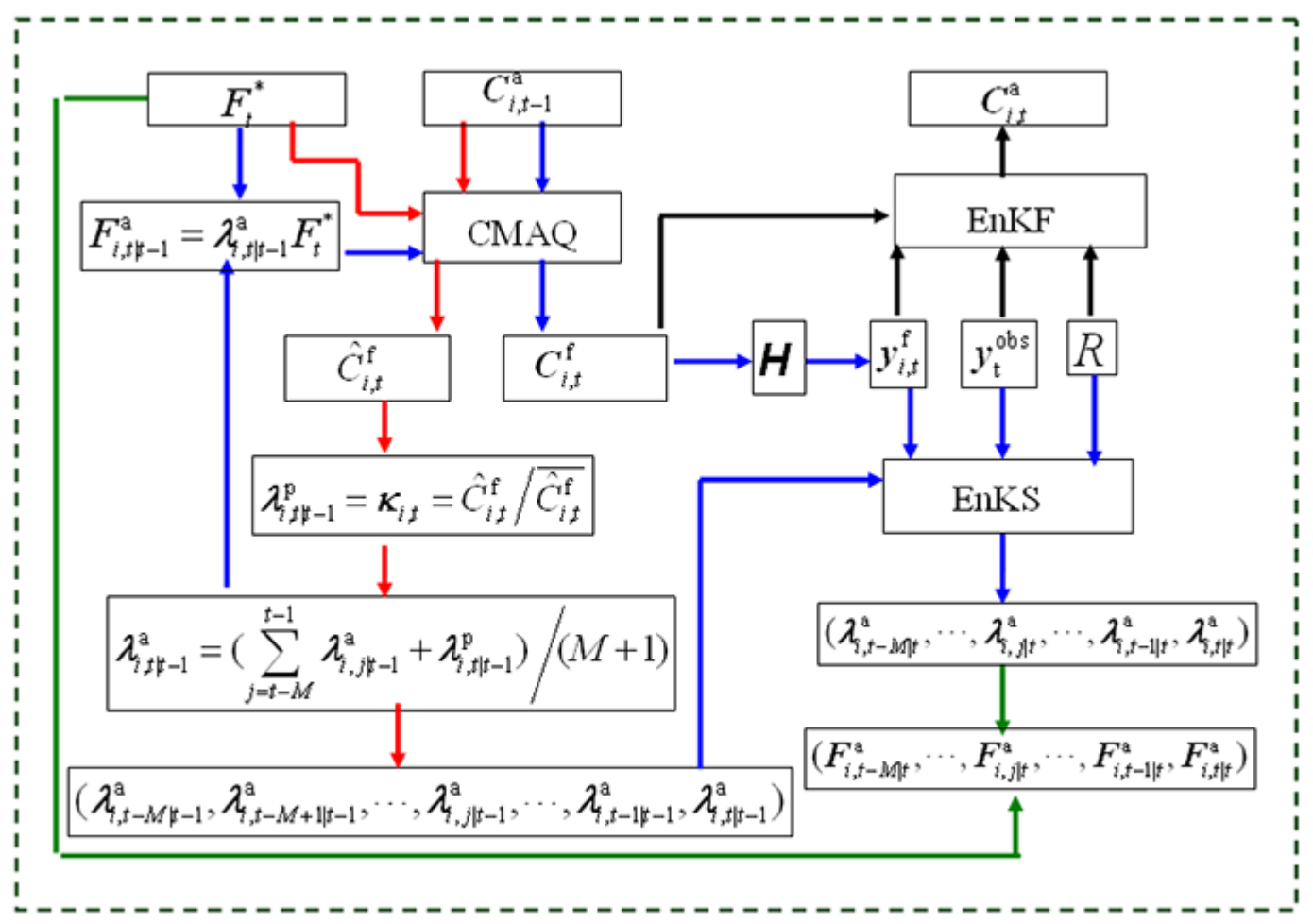

Figure 2. Flowchart of the CFI-CMAQ system used to optimize surface $\mathrm{CO}_{2}$ fluxes at each assimilation cycle. The system includes the following four parts in turn: (1) forecasting of the linear scaling factors $\lambda_{i, t \mid t-1}^{\mathrm{a}}$ (red arrows); (2) optimization of the scaling factors in the smoother window by EnKS (see Fig. 1) (blue arrows); (3) updating of the flux in the smoother window (green arrows); and (4) assimilation of the $\mathrm{CO}_{2}$ concentration fields at time $t$ by EnKF (black arrows).

the scaling factors in the smoother window. An OSSE was designed to illustrate the difference between our method and the one in which $\lambda_{i, t \mid t-1}^{\mathrm{p}}$ are set to 1 in Sect. 3 .

It is also important to note that, similar to Peters et al. (2007), this dynamical model equation still does not in- clude an error term in the dynamical model, and the model error cannot be estimated yet. However, the covariance inflation is applied to compensate for model errors before optimization, which is addressed in Sect. 2.5. 


\subsection{Optimizing the scaling factors in the smoother window by EnKS}

Substituting $\lambda_{i, t \mid t-1}^{\mathrm{a}}$ into Eq. (1), the $i$ th member of the surface fluxes at time $t, \mathbf{F}_{i, t \mid t-1}^{\mathrm{a}}$, can be generated. Then, forced by $\mathbf{F}_{i, t \mid t-1}^{\mathrm{a}}$, CMAQ was run from time $t-1$ to $t$ to produce the background concentration field $\mathbf{C}_{i, t}^{\mathrm{f}}$ with $\mathbf{C}_{i, t-1}^{\mathrm{a}}$ as initial conditions.

In the current assimilation cycle $t-M \sim t$ (see Fig. 1), the scaling factors to be optimized in the smoother window are $\left(\lambda_{i, t-M \mid t-1}^{\mathrm{a}}, \lambda_{i, t-M+1 \mid t-1}^{\mathrm{a}}, \ldots, \lambda_{i, j \mid t-1}^{\mathrm{a}}, \ldots\right.$, $\left.\lambda_{i, t-1 \mid t-1}^{\mathrm{a}}, \lambda_{i, t \mid t-1}^{\mathrm{a}}\right)$, as stated in the first paragraph of Sect. 2.1. Using the EnKS analysis technique, these scaling factors are updated in turn via

$\lambda_{i, j \mid t}^{\mathrm{a}}=\lambda_{i, j \mid t-1}^{\mathrm{a}}+K_{j, t \mid t-1}^{\mathrm{e}}\left(\mathbf{y}_{t}^{\mathrm{obs}}-\mathbf{y}_{i, t}^{\mathrm{f}}+v_{i, t}\right)$,

$(i=1, \ldots, N, j=t-M, \ldots, t)$,

$\mathbf{K}_{j, t \mid t-1}^{\mathrm{e}}=\mathbf{S}_{j, t \mid t-1}^{\mathrm{e}} H^{T}\left(H \mathbf{S}_{t, t \mid t-1}^{\mathrm{e}} H^{T}+\mathbf{R}\right)^{-1}$,

$\mathbf{S}_{j, t \mid t-1}^{\mathrm{e}}=\frac{1}{N-1} \sum_{i=1}^{N}\left[\lambda_{i, j \mid t-1}^{\mathrm{a}}-\overline{\lambda_{i, j \mid t-1}^{\mathrm{a}}}\right]\left[\lambda_{i, t \mid t-1}^{\mathrm{a}}-\overline{\lambda_{i, t \mid t-1}^{\mathrm{a}}}\right]^{T}$,

$\mathbf{S}_{t, t \mid t-1}^{\mathrm{e}}=\frac{1}{N-1} \sum_{i=1}^{N}\left[\lambda_{i, t \mid t-1}^{\mathrm{a}}-\overline{\lambda_{i, t \mid t-1}^{\mathrm{a}}}\right]\left[\lambda_{i, t \mid t-1}^{\mathrm{a}}-\overline{\lambda_{i, t \mid t-1}^{\mathrm{a}}}\right]^{T}$,

$\mathbf{y}_{i, t}^{\mathrm{f}}=H\left(\phi_{t-1 \rightarrow t}\left(\lambda_{i, t \mid t-1}^{\mathrm{a}}\right)\right)=H\left(\mathbf{C}_{i, t}^{\mathrm{f}}\right)$,

where $\mathbf{K}_{j, t \mid t-1}^{\mathrm{e}}$ is the Kalman gain matrix of EnKS, $\mathbf{y}_{t}^{\text {obs }}$ is the observation vector measured at time $t$ and $\mathbf{y}_{i, t}^{\mathrm{f}}$ is the simulated values, $v_{i, t}$ is a random normal distribution perturbation field with zero mean, $\mathbf{S}_{j, t \mid t-1}^{\mathrm{e}}$ is the background error cross-covariance between the state vector $\lambda_{i, j \mid t-1}^{\mathrm{a}}$ and $\lambda_{i, t \mid t-1}^{\mathrm{a}}, \mathbf{S}_{t, t \mid t-1}^{\mathrm{e}}$ is the background error covariance of the state vector $\lambda_{i, t \mid t-1}^{\mathrm{a}}, H(\cdot)$ is the observation operator that maps the state variable from model space into observation space, $\mathbf{R}$ is the standard deviation representing the measurement errors, and $\phi(\cdot)$ is the atmospheric transport model.

In actual implementations, it is unnecessary to calculate $\mathbf{S}_{j, t \mid t-1}^{\mathrm{e}}$ and $\mathbf{S}_{t, t \mid t-1}^{\mathrm{e}}$ separately. $\mathbf{S}_{j, t \mid t-1}^{\mathrm{e}} H^{T}$ and $H \mathbf{S}_{t, t \mid t-1}^{\mathrm{e}} H^{T}$ can be calculated as a whole by

$\mathbf{S}_{j, t \mid t-1}^{\mathrm{e}} H^{T}=\frac{1}{N-1} \sum_{i=1}^{N}\left[\lambda_{i, j \mid t-1}^{\mathrm{a}}-\overline{\lambda_{i, j \mid t-1}^{\mathrm{a}}}\right]\left[\mathbf{y}_{i, t}^{\mathrm{f}}-\overline{\mathbf{y}_{t}^{\mathrm{f}}}\right]^{T}$,

$H \mathbf{S}_{t, t \mid t-1}^{\mathrm{e}} H^{T}=\frac{1}{N-1} \sum_{i=1}^{N}\left[\mathbf{y}_{i, t}^{\mathrm{f}}-\overline{\mathbf{y}_{t}^{\mathrm{f}}}\right]\left[\mathbf{y}_{i, t}^{\mathrm{f}}-\overline{\mathbf{y}_{t}^{\mathrm{f}}}\right]^{T}$,

$\overline{\mathbf{y}_{t}^{\mathrm{f}}}=H\left(\overline{\mathbf{C}_{t}^{\mathrm{f}}}\right)=H\left(\frac{1}{N} \sum_{i=1}^{N} \mathbf{C}_{i, t}^{\mathrm{f}}\right)$.

After $\quad$ EnKS, $\quad\left(\lambda_{i, t-M \mid t}^{\mathrm{a}}, \lambda_{i, t-M+1 \mid t}^{\mathrm{a}}, \ldots, \lambda_{i, j \mid t}^{\mathrm{a}}, \ldots\right.$ $\left., \lambda_{i, t-1 \mid t}^{\mathrm{a}}, \lambda_{i, t \mid t}^{\mathrm{a}}\right)$ are gained. Then the corresponding fluxes in the smoother window $\left(\mathbf{F}_{i, t-M \mid t}^{\mathrm{a}}, \mathbf{F}_{i, t-M+1 \mid t}^{\mathrm{a}}, \ldots, \mathbf{F}_{i, j \mid t}^{\mathrm{a}}, \ldots, \mathbf{F}_{i, t-1 \mid t}^{\mathrm{a}}, \mathbf{F}_{i, t \mid t}^{\mathrm{a}}\right)$ can be gained (see the green arrows in the flowchart in Fig. 2) by substituting $\left(\lambda_{i, t-M \mid t}^{\mathrm{a}}, \lambda_{i, t-M+1 \mid t}^{\mathrm{a}}, \ldots, \lambda_{i, j \mid t}^{\mathrm{a}}, \ldots, \lambda_{i, t-1 \mid t}^{\mathrm{a}}, \lambda_{i, t \mid t}^{\mathrm{a}}\right) \quad$ into Eq. (1).

Then the ensemble mean values of the assimilated fluxes in the smoother window can be calculated via,

$\overline{\mathbf{F}_{i, j \mid t}^{\mathrm{a}}}=\frac{1}{N} \sum_{i=1}^{N} \mathbf{F}_{i, j \mid t}^{\mathrm{a}},(j=t-M, \ldots, t)$.

Finally, those ensemble mean assimilated fluxes which are before the next smoother window and will not be updated by the succeeding observations are regarded as the final optimized fluxes. We referred to them as $\overline{\mathbf{F}_{t}^{\mathrm{a}}}$ for simplicity.

\subsection{Assimilating the $\mathrm{CO}_{2}$ concentration fields at time $t$ by EnKF}

The analysis of $\mathrm{CO}_{2}$ concentrations fields at time $t$ in the EnKF scheme is updated via

$\mathbf{C}_{i, t}^{\mathrm{a}}=\mathbf{C}_{i, t}^{\mathrm{f}}+\mathbf{K}\left(\mathbf{y}_{t}^{\mathrm{obs}}-\mathbf{y}_{t}^{\mathrm{f}}+v_{i, t}\right)$,

$\mathbf{K}=\mathbf{P}^{\mathrm{f}} H^{T}\left(H \mathbf{P}^{\mathrm{f}} H^{T}+\mathbf{R}\right)^{-1}$,

where $\mathbf{K}$ is the Kalman gain matrix of EnKF, $\mathbf{P}^{\mathbf{f}}$ is the background error covariance among the background $\mathrm{CO}_{2}$ concentration fields $\mathbf{C}_{i, t}^{\mathrm{f}}$.

In the actual application, $\mathbf{P}^{\mathrm{f}} H^{T}$ and $H \mathbf{P}^{\mathrm{f}} H^{T}$ can be calculated as a whole by

$$
\begin{aligned}
& \mathbf{P}^{\mathrm{f}} H^{T}=\frac{1}{N-1} \sum_{i=1}^{N}\left[\mathbf{C}_{i, t}^{\mathrm{f}}-\overline{\mathbf{C}_{t}^{\mathrm{f}}}\right]\left[\mathbf{y}_{i, t}^{\mathrm{f}}-\overline{\mathbf{y}_{t}^{\mathrm{f}}}\right]^{T}, \\
& H \mathbf{P}^{\mathrm{f}} H^{T}=\frac{1}{N-1} \sum_{i=1}^{N}\left[\mathbf{y}_{i, t}^{\mathrm{f}}-\overline{\mathbf{y}_{t}^{\mathrm{f}}}\right]^{T}\left[\mathbf{y}_{i, t}^{\mathrm{f}}-\overline{\mathbf{y}_{t}^{\mathrm{f}}}\right]^{T}, \\
& \overline{\mathbf{C}_{t}^{\mathrm{f}}}=\frac{1}{N} \sum_{i=1}^{N} \mathbf{C}_{i, t}^{\mathrm{f}} .
\end{aligned}
$$

Finally, the ensemble mean values of the assimilated $\mathrm{CO}_{2}$ concentrations fields can be gained via

$\overline{\mathbf{C}_{t}^{\mathrm{a}}}=\frac{1}{N} \sum_{i=1}^{N} \mathbf{C}_{i, t}^{\mathrm{a}}$,

where $\overline{\mathbf{C}_{t}^{\mathrm{a}}}$ is regarded as the final analysing concentration field.

\subsection{The observation operator}

As mentioned above, the observation operator $H(\cdot)$ transforms the state variable from model space into observation space. Usually, it is the spatial bilinear interpolator for traditional ground-based observations. Since the GOSAT $\mathrm{X}_{\mathrm{CO}_{2}}$ retrieval is a weighted $\mathrm{CO}_{2}$ column average, the simulated 
$\mathrm{X}_{\mathrm{CO}_{2}}$ should be calculated with the same weighted column average method (Connor et al., 2008; Crisp et al., 2010, 2012; O'Dell et al., 2012). Hence, the observation operator to assimilate the GOSAT $\mathrm{X}_{\mathrm{CO}_{2}}$ retrieval is

$\mathbf{y}_{i, t}^{\mathrm{f}}=H\left(\phi_{t-1 \rightarrow t}\left(\lambda_{i, t \mid t-1}^{\mathrm{a}}\right)\right)=H\left(\mathbf{C}_{i, t}^{\mathrm{f}}\right)=\mathbf{y}^{\text {priori }}$

$+\mathbf{h}^{T} \mathbf{a}_{\mathrm{CO}_{2}}\left(S\left(\mathbf{C}_{i, t}^{\mathrm{f}}\right)-\mathbf{f}^{\text {priori }}\right)$,

where $\mathbf{y}_{i, t}^{\mathrm{f}}$ is the simulated $\mathrm{X}_{\mathrm{CO}_{2}} ; \mathbf{y}^{\text {priori }}$ is the a priori $\mathrm{CO}_{2}$ column average used in the GOSAT $\mathrm{X}_{\mathrm{CO}_{2}}$ retrieval process; $S(\cdot)$ is the spatial bilinear interpolation operator that interpolates the simulated fields to the GOSAT $\mathrm{X}_{\mathrm{CO}_{2}}$ locations to obtain the simulated $\mathrm{CO}_{2}$ vertical profiles there; $f^{\text {priori is the }}$ a priori $\mathrm{CO}_{2}$ vertical profile used in the retrieval process; $h$ is the pressure weighting function, which indicates the contribution of the retrieved value from each layer of the atmosphere; and $\mathbf{a}_{\mathrm{CO}_{2}}$ is the normalized averaging kernel.

\subsection{Covariance inflation and localization}

In order to keep the ensemble spread of the $\mathrm{CO}_{2}$ concentrations at a certain level and compensate for transport model error to prevent filter divergence, covariance inflation is applied before updating the $\mathrm{CO}_{2}$ concentrations. So,

$\left(\mathbf{C}_{i, t}^{\mathrm{f}}\right)_{\text {new }}=\alpha\left(\mathbf{C}_{i, t}^{\mathrm{f}}-\overline{\mathbf{C}_{i, t}^{\mathrm{f}}}\right)+\overline{\mathbf{C}_{i, t}^{\mathrm{f}}}$,

where $\alpha$ is the inflation factor of $\mathrm{CO}_{2}$ concentrations and $\left(\mathbf{C}_{i, t}^{\mathrm{f}}\right)_{\text {new }}$ is the final field used for data assimilation.

Similarly, covariance inflation is also used to keep the ensemble spread of the prior scaling factors at a certain level and compensate for dynamical model error. Hence,

$\left(\lambda_{i, t \mid t-1}^{\mathrm{p}}\right)_{\text {new }}=\beta\left(\lambda_{i, t \mid t-1}^{\mathrm{p}}-\overline{\lambda_{i, t \mid t-1}^{\mathrm{p}}}\right)+\overline{\lambda_{i, t \mid t-1}^{\mathrm{p}}}$,

where $\beta$ is the inflation factor of scaling factors and $\left(\lambda_{i, t \mid t-1}^{\mathrm{p}}\right)_{\text {new }}$ is the final scaling factors used for data assimilation.

In addition, the Schur product is utilized to filter the remote correlation resulting from the spurious long-range correlations (Houtekamer and Mitchell 2001). Hence, the Kalman gain matrix $\mathbf{K}_{j, t \mid t-1}^{\mathrm{e}}$ and $\mathbf{K}$ are updated via

$$
\begin{aligned}
& \mathbf{K}_{j, t \mid t-1}^{\mathrm{e}}=\left[\left(\rho \circ \mathbf{S}_{j, t \mid t-1}^{\mathrm{e}}\right) H^{T}\left(H\left(\rho \circ \mathbf{P}_{t, t \mid t-1}^{\mathrm{e}}\right) H^{T}+\mathbf{R}\right)^{-1},\right. \\
& \mathbf{K}=\left[\left(\rho \circ \mathbf{P}^{\mathbf{f}}\right) H^{T}\right]\left[\left(H\left(\rho \circ \mathbf{P}^{\mathrm{f}}\right) H^{T}+\mathbf{R}\right]^{-1},\right.
\end{aligned}
$$

where the filtering matrix $\rho$ is calculated using the formula

$$
C_{0}(r, c)=\left\{\begin{array}{c}
-\frac{1}{4}\left(\frac{|r|}{c}\right)^{5}+\frac{1}{2}\left(\frac{|r|}{c}\right)^{4}+\frac{5}{8}\left(\frac{|r|}{c}\right)^{3}-\frac{5}{3}\left(\frac{|r|}{c}\right)^{2}+1,0 \leq|r| \leq c \\
\frac{1}{12}\left(\frac{|r|}{c}\right)^{5}-\frac{1}{2}\left(\frac{|r|}{c}\right)^{4}+\frac{5}{8}\left(\frac{|r|}{c}\right)^{3}+ \\
\frac{5}{3}\left(\frac{|r|}{c}\right)^{2}-5\left(\frac{|r|}{c}\right)+4-\frac{2}{3}\left(\frac{c}{|r|}\right), c \leq|r| \leq 2 c \\
0, c \leq|r|
\end{array},\right.
$$

where $c$ is the element of the localization Schur radius. The matrix $\rho$ can filter the small background error correlations associated with remote observations through the Schur product (Tian et al., 2011); and the Schur product tends to reduce the effect of those observations smoothly at intermediate distances due to the smooth and monotonically decreasing of the filtering matrix.

\section{OSSEs for evaluation of CFI-CMAQ}

A set of OSSEs were designed to quantitatively assess the performance of CFI-CMAQ. The setup of the experiments and the results are described in this section.

\subsection{Experimental setup}

The chemical transport model utilized was RAMS-CMAQ (Zhang et al., 2002), in which $\mathrm{CO}_{2}$ was treated as an inert tracer. The model domain was $6654 \times 5440 \mathrm{~km}^{2}$ on a rotated polar stereographic map projection centred at $\left(35.0^{\circ} \mathrm{N}\right.$, $\left.116.0^{\circ} \mathrm{E}\right)$, with a horizontal grid resolution of $64 \times 64 \mathrm{~km}^{2}$ and 15 vertical layers in the $\sigma_{z}$-coordinate system, unequally spaced from the surface to approximately $23 \mathrm{~km}$. The initial fields and boundary conditions of the $\mathrm{CO}_{2}$ concentrations were interpolated from the simulated $\mathrm{CO}_{2}$ fields of CarbonTracker 2011 (Peters et al., 2007). The prior surface $\mathrm{CO}_{2}$ fluxes included biosphere-atmosphere $\mathrm{CO}_{2}$ fluxes, ocean-atmosphere $\mathrm{CO}_{2}$ fluxes, anthropogenic emissions, and biomass-burning emissions (Kou et al., 2013),

$$
\begin{aligned}
& F^{\mathrm{p}}(x, y, z, t)=F_{\text {bio }}(x, y, z, t)+F_{\text {oce }}(x, y, z, t) \\
& +F_{\text {ff }}(x, y, z, t)+F_{\text {fire }}(x, y, z, t),
\end{aligned}
$$

where $F^{\mathrm{p}}(x, y, z, t)$ (referred to as $\left.\mathbf{F}_{t}^{\mathrm{p}}\right)$ was the prior surface $\mathrm{CO}_{2}$ flux; $F_{\text {bio }}(x, y, z, t)$ and $F_{\text {oce }}(x, y, z, t)$ were the biosphere-atmosphere and ocean-atmosphere $\mathrm{CO}_{2}$ fluxes, respectively, which were obtained from the optimized results of CarbonTracker 2011 (Peters et al., 2007); $F_{\mathrm{ff}}(x, y, z, t)$ was fossil fuel emissions, adopted from the Regional Emission inventory in ASia (REAS, 2005 Asia monthly mean emission inventory) with a spatial resolution of $0.5^{\circ} \times 0.5^{\circ}$ (Ohara et al., 2007); and $F_{\text {fire }}(x, y, z, t)$ was biomassburning emissions, provided by the monthly mean inventory at a spatial resolution of $0.5^{\circ} \times 0.5^{\circ}$ from the Global Fire Emissions Database, Version 3 (GFED v3) (van der Werf et al., 2010). Among all these fluxes, $F_{\text {bio }}(x, y, z, t)$, $F_{\text {oce }}(x, y, z, t)$ and $F_{\text {ff }}(x, y, z, t)$ had nonzero values at model level 1 , while they all were zeros at the other 14 levels. However, $F_{\text {fire }}(x, y, z, t)$ had nonzero values at model level $1 \sim 5$ and they were all zeros at other the 10 levels. So, all fluxes in this paper were the function of $(x, y, z, t)$ for convenience.

Firstly, the prior flux $\mathbf{F}_{t}^{\mathrm{p}}$ was assumed as the true surface $\mathrm{CO}_{2}$ flux in all of the following OSSEs. Forced by $\mathbf{F}_{t}^{\mathrm{p}}$, the RAMS-CMAQ model was run to produce the artificial true $\mathrm{CO}_{2}$ concentration results $C^{\mathrm{p}}(x, y, z, t)$ (referred to as $\mathbf{C}_{t}^{\mathrm{p}}$ in 

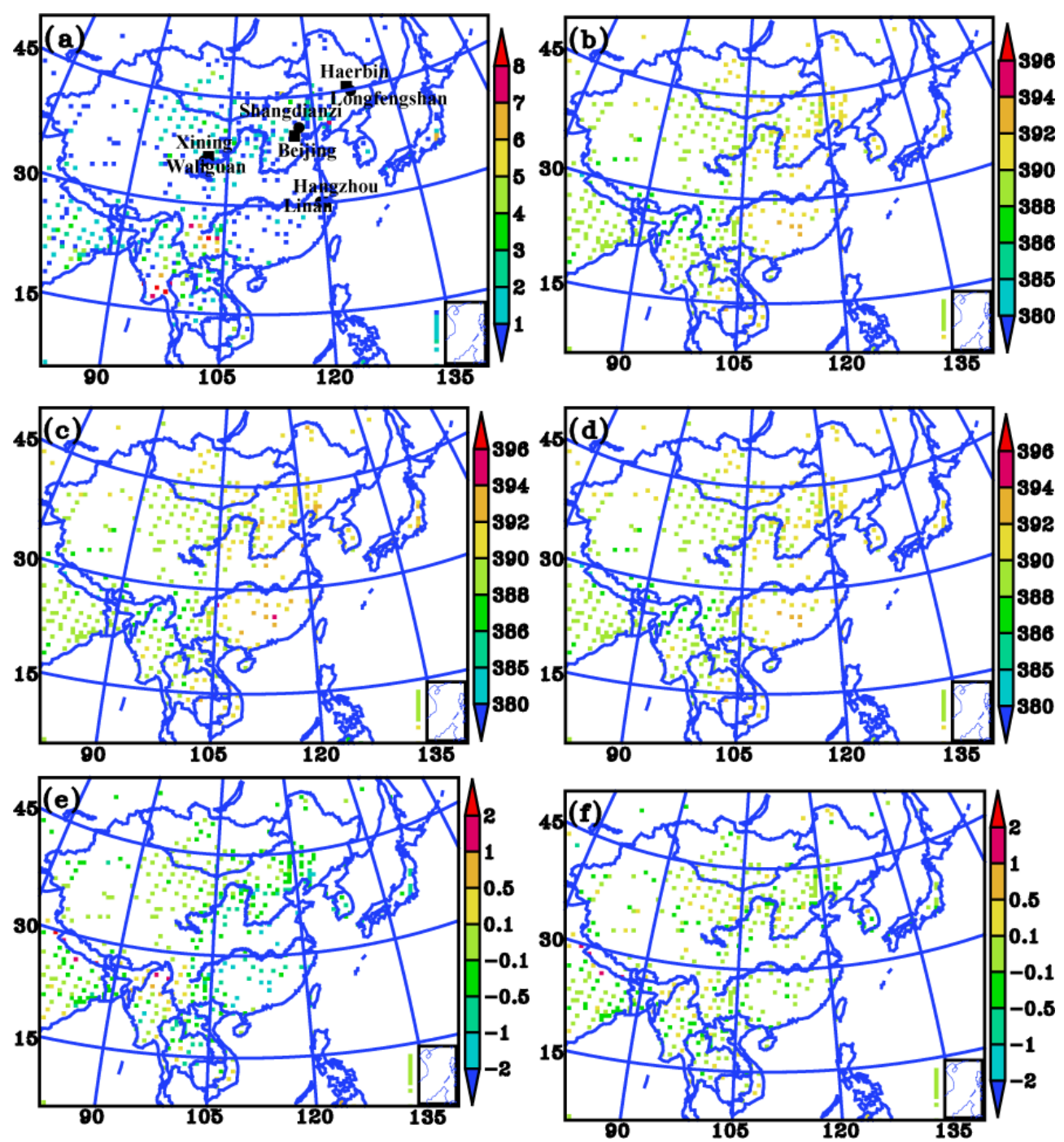

Figure 3. (a) Total number of observations in February 2010 in the model grid. Each symbol indicates the total number of all GOSAT $\mathrm{X}_{\mathrm{CO}_{2}}$ measurements in the corresponding model grid. Monthly mean values in February 2010 of $(\mathbf{b}) \mathrm{X}_{\mathrm{CO}_{2}}^{\mathrm{p}}$, column mixing ratio of $\mathbf{C}_{t}^{\mathrm{p}}$; (c) $\mathrm{X}_{\mathrm{CO}_{2}}^{\mathrm{f}}$, column mixing ratio of $\mathbf{C}_{t}^{\mathrm{f}}$; (d) $\overline{X_{\mathrm{CO}_{2}}^{\mathrm{a}}}$, column mixing ratio of $\overline{\mathbf{C}_{t}^{\mathrm{a}}}$; (e) $\mathrm{X}_{\mathrm{CO}_{2}}^{\mathrm{p}}-X_{\mathrm{CO}_{2}}^{\mathrm{f}}$; and (f) $\mathrm{X}_{\mathrm{CO}_{2}}^{\mathrm{p}}-\overline{X_{\mathrm{CO}_{2}}}$. All column mixing ratios are column-averaged with real GOSAT $\mathrm{X}_{\mathrm{CO}_{2}}$ averaging kernels at GOSAT $\mathrm{X}_{\mathrm{CO}_{2}}$ locations. Each symbol indicates the monthly average value of all $\mathrm{X}_{\mathrm{CO}_{2}}$ estimates in the model grid. $\overline{\mathrm{C}_{t}^{\mathrm{a}}}$ are the ensemble mean values of the assimilated $\mathrm{CO}_{2}$ concentrations fields of a CFI-CMAQ OSSE, in which the lag-window was 9 days and $\beta$ was 70. They are the same OSSE in Figs. 3-6.

the following). Then, the artificial GOSAT observations $\mathbf{y}_{t}^{\text {obs }}$ (or $\mathrm{X}_{\mathrm{CO}_{2}}^{\mathrm{p}}$ ) were generated by substituting $\mathbf{C}_{t}^{\mathrm{p}}$ into the observation operator in Eq. (16). The retrieval information of GOSAT $\mathrm{X}_{\mathrm{CO}_{2}}\left(\mathbf{y}^{\text {priori }}, f^{\text {priori }}, h\right.$ and $\left.\mathbf{a}_{\mathrm{CO}_{2}}\right)$ needed in Eq. (16) were gained from the v2.9 Atmospheric $\mathrm{CO}_{2}$ Observations from Space (ACOS) Level 2 standard data products, which only utilized the SWIR observations. Only data classified into the "Good" category were utilized in this study. During the retrieval process, most of the soundings (such as data with a solar zenith angle greater than $85^{\circ}$, or data not in clear sky conditions, or data collected over the ocean but not in glint, etc.) were not processed, so typically data products for the "good" category contained only 10-100 soundings per satellite orbit (Osterman et al., 2011), and there were only $0 \sim 60$ samples per orbit in the study model domain generally. Fig. 3a also showed the total number of "good" GOSAT $\mathrm{X}_{\mathrm{CO}_{2}}$ observations for each model grid in February in 2010. There were relatively more observations over most continental regions of the study domain except some regions in NorthEast and South China. The total numbers ranged from 1 to 8. However, there were almost no data over the oceans of the study domain. 

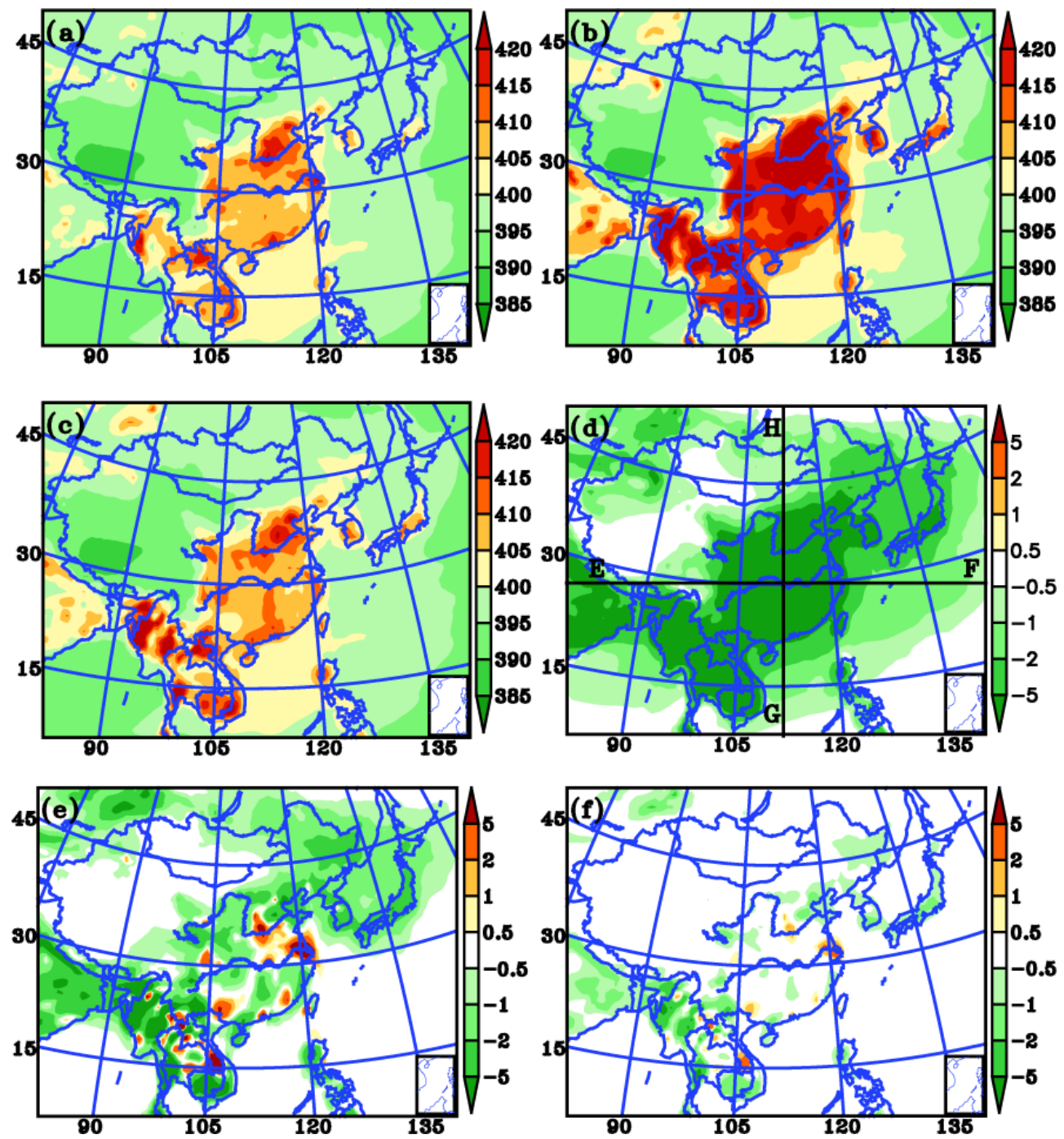

Figure 4. Monthly mean values of (a) $\mathbf{C}_{t}^{\mathrm{p}}$, the artificial true simulations driven by the prior surface $\mathrm{CO}_{2}$ fluxes $\mathbf{F}_{t}^{\mathrm{p}}$; (b) $\mathbf{C}_{t}^{\mathrm{f}}$, the background simulations driven by magnified surface $\mathrm{CO}_{2}$ fluxes $\mathbf{F}_{t}^{*}=(1.8+\delta(x, y, z, t)) \mathbf{F}_{t}^{\mathrm{p}} ;(\mathbf{c}) \overline{\mathbf{C}_{t}^{\mathrm{a}}}$, the ensemble mean values of the assimilated $\mathrm{CO}_{2}$ concentrations fields; (d) $\mathbf{C}_{t}^{\mathrm{p}}-\mathbf{C}_{t}^{\mathrm{f}}$; (e) $\mathbf{C}_{t}^{\mathrm{p}}-\overline{\mathbf{C}_{t}^{\mathrm{a}}}$; and (f) $100 *\left(\mathbf{C}_{t}^{\mathrm{p}}-\overline{\mathbf{C}_{t}^{\mathrm{a}}}\right) / \mathbf{C}_{t}^{\mathrm{p}}$ at model-level 1 in February 2010. Black lines EF and GH indicate the positions of the cross sections shown in Fig. 5.

Secondly, the prescribed surface $\mathrm{CO}_{2}$ fluxes series $\mathbf{F}_{t}^{*}$ were created by

$\mathbf{F}_{t}^{*}=(1.8+\delta(x, y, z, t)) \mathbf{F}_{t}^{\mathrm{p}}$,

where $\delta$ was a random number. They were standard normal distribution time series at each grid in the integration period of our numerical experiment. Driven by $\mathbf{F}_{t}^{*}$, the RAMSCMAQ model was integrated to obtain the $\mathrm{CO}_{2}$ simulations $C^{\mathrm{f}}(x, y, z, t)$ (referred to as $\mathbf{C}_{t}^{\mathrm{f}}$ hereafter). Then, the column-averaged concentrations $\mathrm{X}_{\mathrm{CO}_{2}}^{\mathrm{f}}$ were obtained using Eq. (16).

The performance of CFI-CMAQ was evaluated through a group of well-designed OSSEs, and the goal of each OSSE was to retrieve the true fluxes $\mathbf{F}_{t}^{\mathrm{p}}$ from given true observa- tions $\mathrm{X}_{\mathrm{CO}_{2}}^{\mathrm{p}}$ and "wrong" fluxes $\mathbf{F}_{t}^{*}$. In all the OSSEs, we assimilated artificial observations $\mathrm{X}_{\mathrm{CO}_{2}}^{\mathrm{p}}$ about three times a day since GOSAT has about three orbits in the study model domain. If there were some observations, CFI-CMAQ paused to assimilate. Otherwise, it continued simulating. The default ensemble size $N$ was 48, the measurement errors were 1.5 ppmv, the standard localization Schur radius $c$ was $1280 \mathrm{~km}$ (20 grid spacing), and the covariance inflation factor of concentrations $\alpha$ was 1.1. The referenced lag-window was 9 days and the covariance inflation factor of the prior scaling factors $\beta$ was 70 . Since the smoother window was very important for $\mathrm{CO}_{2}$ transportation and $\beta$ was a newly introduced parameter, both these parameters were further investigated by several numerical sensitivity experiments. The 

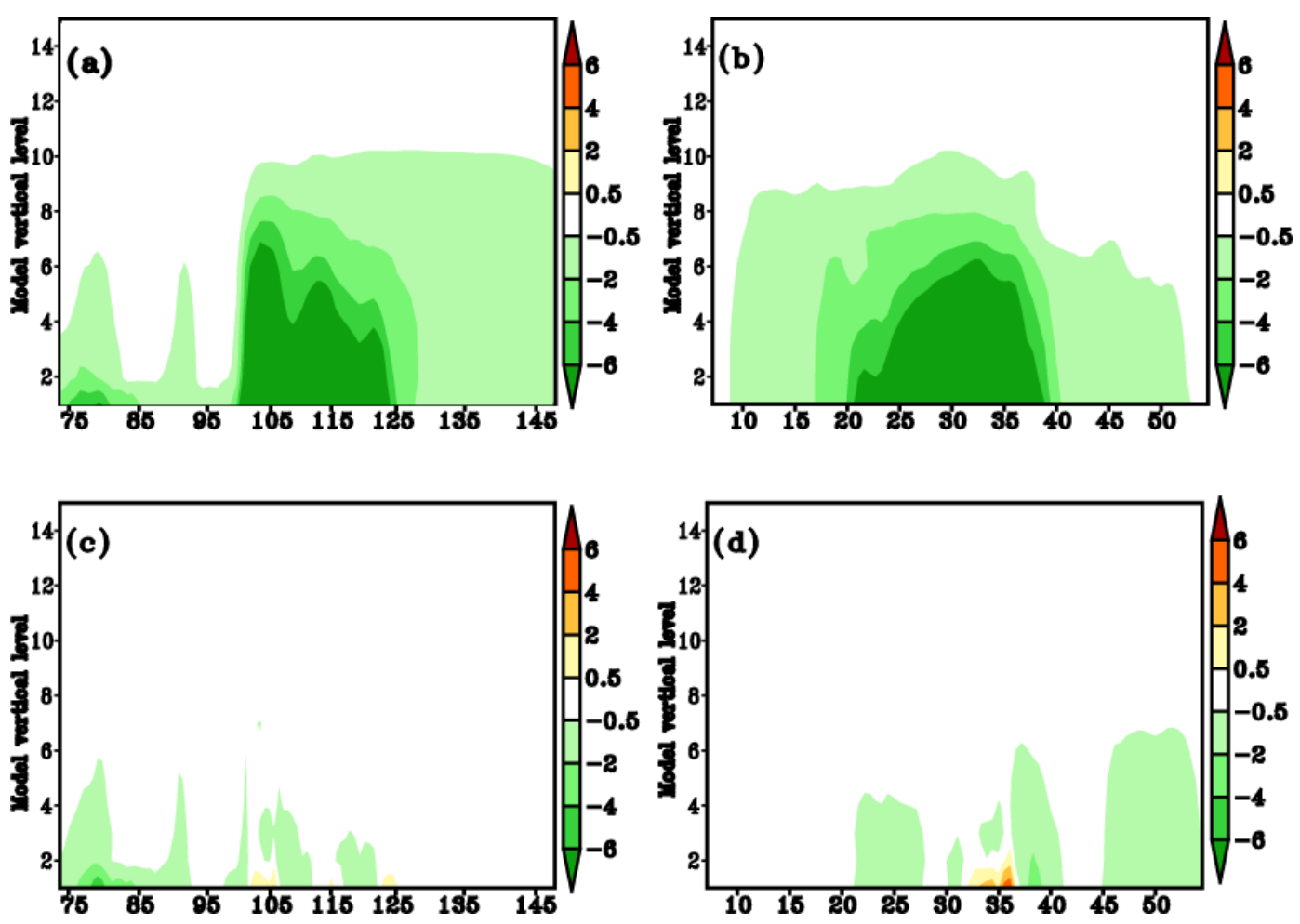

Figure 5. Monthly mean cross sections of $\mathbf{C}_{t}^{\mathrm{p}}-\mathbf{C}_{t}^{\mathrm{f}}$ along line (a) EF and (b) GH, and monthly mean cross sections of $\mathbf{C}_{t}^{\mathrm{p}}-\overline{\mathbf{C}_{t}^{\mathrm{a}}}$ along line (c) EF and (d) GH (cross section lines shown in Fig. 4d) in February 2010.

primary focus of this paper was to describe the assimilation methodology, so all the numerical experiments started on 1 January 2010 and ended on 30 March 2010.

As for the initialization of CFI-CMAQ, only the ensemble of background concentration fields $C_{i, 0}^{\mathrm{f}}$ needed to be initialized at the time $t=0$ because the values of $\lambda_{i, t \mid t-1}^{\mathrm{a}}$ were updated using the persistence dynamical model. In practice, the mean concentration fields at $t=0$ are interpolated from the simulated $\mathrm{CO}_{2}$ fields of CarbonTracker 2011 (Peters et al., 2007). The ensemble members of the background concentration fields were created by adding random vectors. The mean values of the random vectors were zero and the variances were 2.5 percent of the mean concentration fields. The atmospheric transport model then integrated from time $t=0$ to $t=1$ driven by $\mathbf{F}_{t}^{*}$ with $C_{i, 0}^{\mathrm{f}}$ as initial conditions to produce the $\mathrm{CO}_{2}$ concentration fields $\hat{C}_{i, 1}^{\mathrm{f}}$. Subsequently, the first prior linear scaling factors, $\lambda_{i, 1 \mid 0}^{\mathrm{p}}$, could be calculated by applying $\hat{C}_{i, 1}^{\mathrm{f}}$. Assuming that $\lambda_{i, 1 \mid 0}^{\mathrm{a}}=\lambda_{i, 1 \mid 0}^{\mathrm{p}}, \lambda_{i, 1 \mid 0}^{\mathrm{a}}$ are gained, finally. For the first assimilation cycle, the lag-window was only one (that is, only $\lambda_{i, 1 \mid 0}^{\mathrm{a}}$ needed to be optimized in the first assimilation cycle). It increased for the first dozens of assimilation cycles until it reached $\mathrm{M}+1$ as CFI-CMAQ continued to assimilate observations. Once the system was initialized, all future scaling factors could be created using the persistence dynamical model, which associated the smoothing operator with the atmospheric transport model.
In order to illustrate the limitation using only the smoothing operator as the persistence dynamical model to generate all future scaling factors, another OSSE (referred to as the reference experiment to distinguish it from the abovementioned CFI-CMAQ OSSEs) was designed to optimize the surface $\mathrm{CO}_{2}$ fluxes at grid scale. The reference experiment was under the same assimilation framework as CFICMAQ except that all $\lambda_{i, t \mid t-1}^{\mathrm{p}}$ were set to 1 (Peters et al., 2007). Beside that, the initialization procedure of the reference experiment was different from that of the CFI-CMAQ. In practice, both the ensemble of background concentration fields at $t=0, C_{i, 0}^{\mathrm{f}}$, and the ensemble members of the scaling factors at $t=1, \lambda_{i, 1 \mid 0}^{\mathrm{a}}$, needed to be initialized because they could not be generated in other ways (Peters et al., 2005). The initial concentration fields $C_{i, 0}^{\mathrm{f}}$ were created using the same method as that used to generate $C_{i, 0}^{\mathrm{f}}$ for the CFI-CMAQ OSSEs. The ensemble members of the scaling factors $\lambda_{i, 1 \mid 0}^{\mathrm{a}}$ were rand fields. Their mean values were 1 and their variances were 0.1. In addition, in order to keep the ensemble spread of the scaling factors $\lambda_{i, t \mid t-1}^{\mathrm{a}}$ at a certain level and compensate for dynamical model error, covariance inflation was also used and the covariance inflation factor of the scaling factors $\lambda_{i, t \mid t-1}^{\mathrm{a}}$ was 1.6. All other parameters are the same as used in the CFI-CMAQ OSSEs. The ensemble size $N$ was 48 , the measurement errors were $1.5 \mathrm{ppmv}$, the standard localization Schur radius $c$ was $1280 \mathrm{~km}$, the covariance infla- 

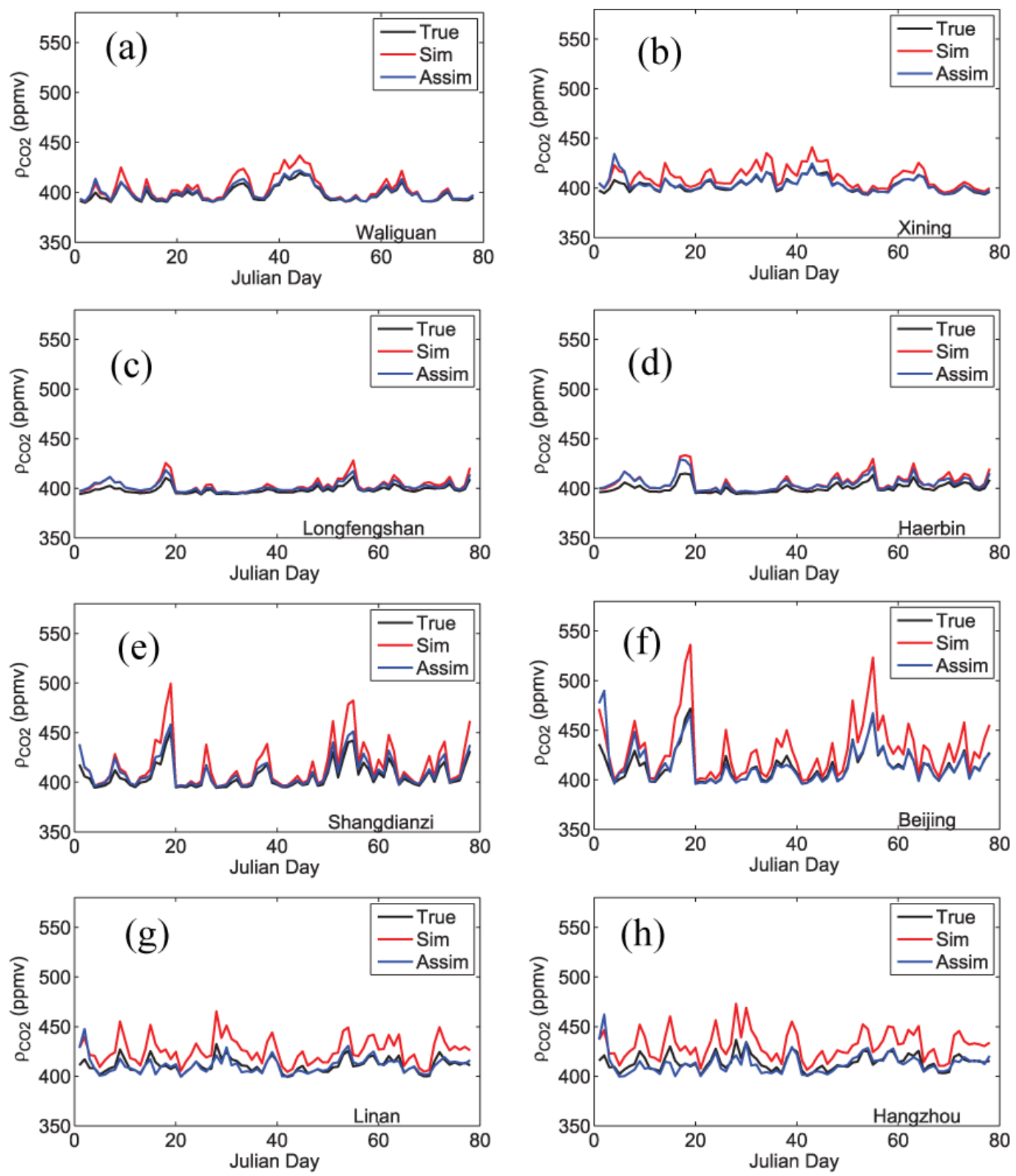

Figure 6. Daily mean time series of $\mathrm{CO}_{2}$ concentrations at national background stations in China and their nearest large cities from 1 January to 20 March 2010 extracted from the artificial true simulations $\mathbf{C}_{t}^{\mathrm{p}}$ (black), background simulations $\mathbf{C}_{t}^{\mathrm{f}}$ (red), and the ensemble mean values of the assimilated $\mathrm{CO}_{2}$ concentrations fields $\overline{\mathbf{C}_{t}^{\mathrm{a}}}$ (blue). All time series were interpolated to the observation locations by the spatial bilinear interpolator method. The sites used are (a) Waliguan $\left(36.28^{\circ} \mathrm{N}, 100.91^{\circ} \mathrm{E}\right)$, (b) Xining $\left(36.56^{\circ} \mathrm{N}, 101.74^{\circ} \mathrm{E}\right)$, (c) Longfengshan $\left(44.73^{\circ} \mathrm{N}\right.$, $\left.127.6^{\circ} \mathrm{E}\right)$, (d) Haerbin $\left(45.75^{\circ} \mathrm{N}, 126.63^{\circ} \mathrm{E}\right),\left(\right.$ e) Shangdianzi $\left(40.65^{\circ} \mathrm{N}, 117.12^{\circ} \mathrm{E}\right)$, (f) Beijing $\left(39.92^{\circ} \mathrm{N}, 116.46^{\circ} \mathrm{E}\right),(\mathrm{g}) \mathrm{Linan}\left(30.3^{\circ} \mathrm{N}\right.$ $\left.119.73^{\circ} \mathrm{E}\right)$, and (h) Hangzhou $\left(30.3^{\circ} \mathrm{N}, 120.2^{\circ} \mathrm{E}\right)$.

tion factor of concentrations $\alpha$ was 1.1, and the lag-window was 9 days.

\subsection{Experimental results}

Essentially, the assimilation part of CFI-CMAQ includes two subsections: one for the $\mathrm{CO}_{2}$ concentration assimilation with EnKF, which can provide convincing $\mathrm{CO}_{2}$ initial analysis fields for the next assimilation cycle; and the other for the $\mathrm{CO}_{2}$ flux optimization with EnKS, which can provide better estimation of the scaling factors for the next time through the persistence dynamical model, except for optimized $\mathrm{CO}_{2}$ fluxes. The performance of the EnKF subsection will be greatly influenced by the validation of the EnKS subsection, or vice versa. Firstly, the performance of CFI-CMAQ will be quantitatively assessed in detail using the assimilated re- 

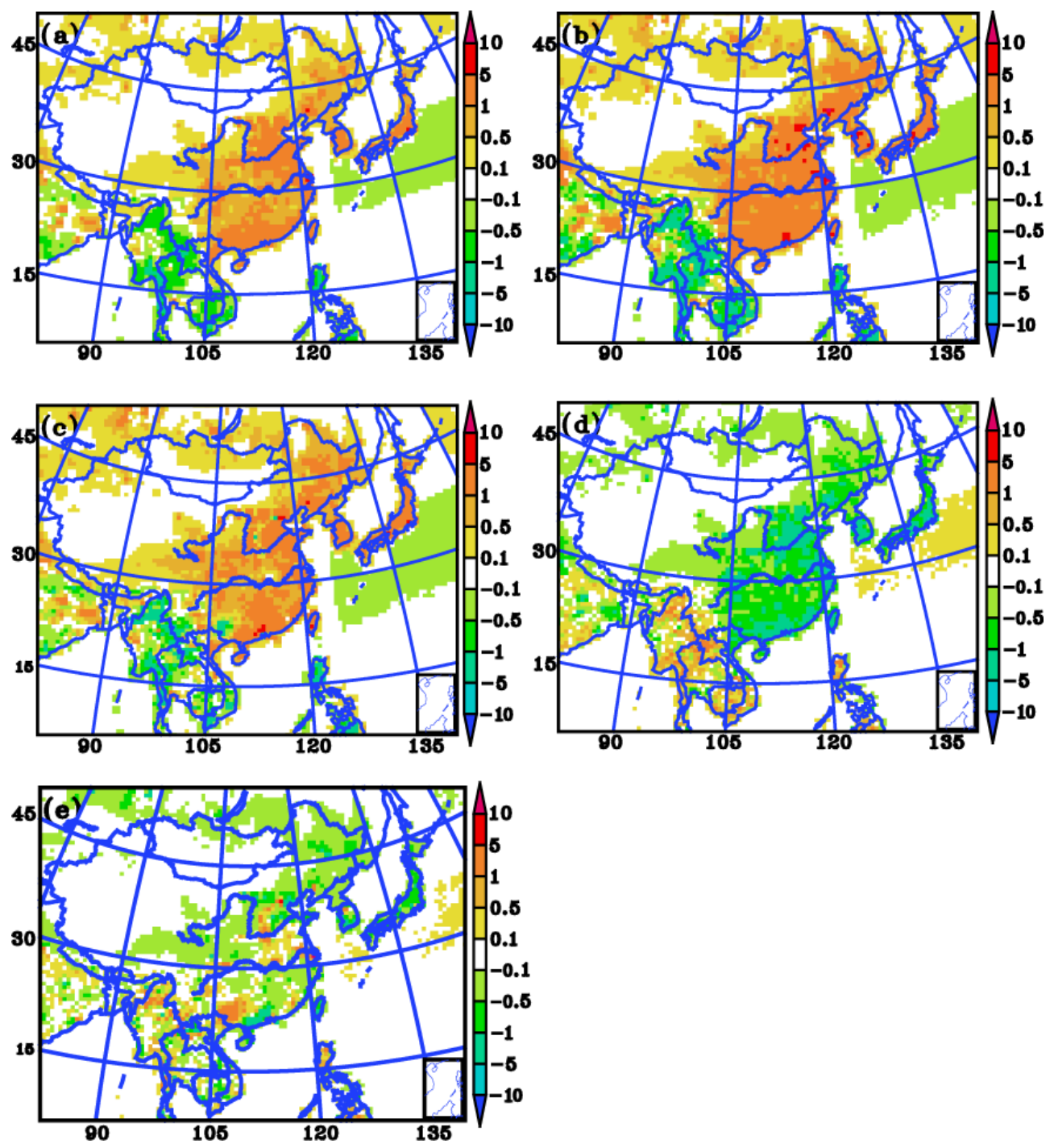

Figure 7. Monthly mean values in February 2010 of (a) $\mathbf{F}_{t}^{\mathrm{p}}$, the prior true surface $\mathrm{CO}_{2}$ fluxes; (b) $\mathbf{F}_{t}^{*}$, the prescribed $\mathrm{CO}_{2}$ surface fluxes, $\mathbf{F}_{t}^{*}=(1.8+\delta(x, y, z, t)) \mathbf{F}_{t}^{\mathrm{p}}$; (c) $\overline{\mathbf{F}_{t}^{\mathrm{a}}}$, the ensemble mean values of the assimilated surface $\mathrm{CO}_{2}$ fluxes; (d) $\mathbf{F}_{t}^{\mathrm{p}}-\mathbf{F}_{t}^{*}$; and (e) $\mathbf{F}_{t}^{\mathrm{p}}-\overline{\mathbf{F}_{t}^{\mathrm{a}}}$ (units: $\mu$ mole $\left.\mathrm{m}^{-2} \mathrm{~s}^{-1}\right) . \overline{\mathbf{F}_{t}^{\mathrm{a}}}$ are the assimilated results of a CFI-CMAQ OSSE, in which the lag-window was 9 days and $\beta$ was 70 . They are the same in Figs. 7-10.

sults of a CFI-CMAQ OSSE, in which the lag-window was 9 days and $\beta$ was 70. The sensitivities of $\beta$ and the lag-window will then be discussed in the following two paragraphs. Finally, the assimilation results of the reference experiment in which $\lambda_{i, t \mid t-1}^{\mathrm{p}}$ were set to 1 will be briefly described at the end of this subsection.

We begin by describing the impacts of assimilating artificial observations $\mathrm{X}_{\mathrm{CO}_{2}}^{\mathrm{p}}$ on $\mathrm{CO}_{2}$ simulations by CFI-CMAQ. As shown in Fig. $4 \mathrm{a}, \mathrm{b}$ and d, the monthly mean values of the background $\mathrm{CO}_{2}$ concentrations $\mathbf{C}_{t}^{\mathrm{f}}$ produced by the magnified surface $\mathrm{CO}_{2}$ fluxes $\mathbf{F}_{t}^{*}$ were much larger than those of the artificial true $\mathrm{CO}_{2}$ concentrations $\mathbf{C}_{t}^{\mathrm{p}}$ produced by the prior surface $\mathrm{CO}_{2}$ fluxes $\mathbf{F}_{t}^{\mathrm{p}}$ near the surface in February 2010. In the east and south of China especially, the magnitude of the difference between $\mathbf{C}_{t}^{\mathrm{p}}$ and $\mathbf{C}_{t}^{\mathrm{f}}$ was at least $6 \mathrm{ppmv}$. Also, as expected, the monthly mean $\mathrm{X}_{\mathrm{CO}_{2}}^{\mathrm{f}}$ was much larger than the monthly mean artificial observations $\mathrm{X}_{\mathrm{CO}_{2}}^{\mathrm{p}}$, and the magnitude of the difference between $\mathrm{X}_{\mathrm{CO}_{2}}^{\mathrm{p}}$ and $\mathrm{X}_{\mathrm{CO}_{2}}^{\mathrm{f}}$ reached 2 ppmv in the east and south of China (see Fig. $3 b, c, e$ ). However, the impact of magnifying surface $\mathrm{CO}_{2}$ fluxes on the $\mathrm{CO}_{2}$ concentrations was primarily below the model-level 10 (approximately $6 \mathrm{~km}$ ), and especially below model-level 7 (approximately $1.6 \mathrm{~km}$ ). Above model-level 10, the differences between $\mathbf{C}_{t}^{\mathrm{p}}$ and $\mathbf{C}_{t}^{\mathrm{f}}$ fell to zero (see Fig. 5a, b). After assimilating $\mathrm{X}_{\mathrm{CO}_{2}}^{\mathrm{p}}$, the analysis $\mathrm{CO}_{2}$ concentrations $\overline{\mathbf{C}_{t}^{\mathrm{a}}}$ was much closer to $\mathbf{C}_{t}^{\mathrm{p}}$ (see Fig. 4c, e, f). The monthly mean difference between $\mathbf{C}_{t}^{\mathrm{p}}$ and $\overline{\mathbf{C}_{t}^{\mathrm{a}}}$ ranged from -2 to 2 ppmv and 


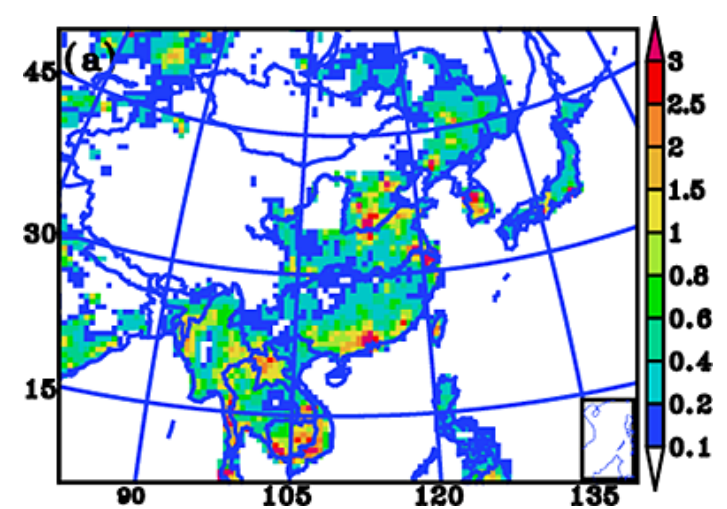

Figure 8. Monthly mean RMSEs of $\overline{\mathbf{F}_{t}^{\mathrm{a}}}$ in February 2010 (units: $\mu$ mole $\mathrm{m}^{-2} \mathrm{~s}^{-1}$ ).

the relative error $\left(\mathbf{C}_{t}^{\mathrm{p}}-\overline{\mathbf{C}_{t}^{\mathrm{a}}}\right) / \mathbf{C}_{t}^{\mathrm{p}}$ ranged from -1 to $1 \%$ in almost the entire model domain at model-level 1 . The monthly mean differences between $\mathbf{C}_{t}^{\mathrm{p}}$ and $\overline{\mathbf{C}_{t}^{\mathrm{a}}}$ were negligible above model-level 2 (see Fig. 5c, d). The monthly mean $\mathrm{X}_{\mathrm{CO}_{2}}^{\mathrm{a}}$ was also closer to $\mathrm{X}_{\mathrm{CO}_{2}}^{\mathrm{p}}$ and the difference between $\mathrm{X}_{\mathrm{CO}_{2}}^{\mathrm{p}}$ and $\mathrm{X}_{\mathrm{CO}_{2}}^{\mathrm{a}}$ ranged from -0.5 to $0.5 \mathrm{ppmv}$. In order to evaluate the general impact of assimilating $\mathrm{X}_{\mathrm{CO}_{2}}^{\mathrm{p}}$ in the surface layer, time series of the daily mean $\mathrm{CO}_{2}$ concentration extracted from the background simulations and the assimilations were compared with the artificial true simulations at four national background stations in China and their nearest large cities. As shown in Fig. 3a, Waliguan is $150 \mathrm{~km}$ away from Xining, Longfengshan is $180 \mathrm{~km}$ away from Haerbin, Shangdianzi is $150 \mathrm{~km}$ away from Beijing, and Linan is $50 \mathrm{~km}$ away from Hangzhou. The assimilated results are shown in Fig. 6 . The background time series were much larger than the artificial true time series, especially at Shangdianzi, Beijing, Linan and Hangzhou, which are strongly influenced by local anthropogenic $\mathrm{CO}_{2}$ emissions. After assimilating $\mathrm{X}_{\mathrm{CO}_{2}}^{\mathrm{p}}$, the assimilated time series were very close to the true time series with negligible bias, as expected, at Waliguan, Xining, Shangdianzi, Beijing, Linan and Hangzhou, especially after the first 10 days, which can be considered the spin-up period. Meanwhile, the improvements at Longfengshan and Haerbin were limited due to the absence of observation data at those locations (see Fig. 3a). Nevertheless, in general, the substantial benefits to the $\mathrm{CO}_{2}$ concentrations in the surface layer of assimilating GOSAT $\mathrm{X}_{\mathrm{CO}_{2}}$ with EnKF are clear. All the results illustrated that CFI-CMAQ can provide a convincing $\mathrm{CO}_{2}$ initial analysis fields for $\mathrm{CO}_{2}$ flux inversion.

The impacts of assimilating $\mathrm{X}_{\mathrm{CO}_{2}}^{\mathrm{p}}$ on surface $\mathrm{CO}_{2}$ fluxes were also highly impressive by CFI-CMAQ. On the whole, the prescribed $\mathrm{CO}_{2}$ surface fluxes $\mathbf{F}_{t}^{*}$ were much larger than the true surface $\mathrm{CO}_{2}$ fluxes $\mathbf{F}_{t}^{\mathrm{p}}$ in February 2010, especially in the east and south of China. The monthly mean difference between $\mathbf{F}_{t}^{*}$ and $\mathbf{F}_{t}^{\mathrm{p}}$ reached $5 \mu$ mole $\mathrm{m}^{-2} \mathrm{~s}^{-1}$ in JingJin-Ji, the Yangtze River delta, and the Pearl River Delta Urban Circle because of the strong local anthropogenic $\mathrm{CO}_{2}$ emissions (see Fig. 7a, b, d). After assimilating $\mathrm{X}_{\mathrm{CO}_{2}}^{\mathrm{p}}$, the ensemble mean of the assimilated surface $\mathrm{CO}_{2}$ fluxes $\overline{\mathbf{F}_{t}^{\mathrm{a}}}$ decreased sharply. Thus, the monthly mean values of $\overline{\mathbf{F}_{t}^{a}}$ were much smaller than $\mathbf{F}_{t}^{*}$ in most of the model domain in February 2010. The pattern of the difference between $\overline{\mathbf{F}_{t}}$ and $\mathbf{F}_{t}^{*}$ was similar to that of the difference between $\mathbf{F}_{t}^{\mathrm{p}}$ and $\mathbf{F}_{t}^{*}$ (see Fig. 7d). The ensemble mean of the assimilated surface $\mathrm{CO}_{2}$ fluxes $\overline{\mathbf{F}_{t}^{\mathrm{a}}}$ were also compared to the artificial true fluxes $\mathbf{F}_{t}^{\mathrm{p}}$, revealing that $\overline{\mathbf{F}_{t}^{\mathrm{a}}}$ was equivalent to $\mathbf{F}_{t}^{\mathrm{p}}$ in most of the model domain. The monthly mean difference between $\overline{\mathbf{F}_{t}^{\mathrm{a}}}$ and $\mathbf{F}_{t}^{\mathrm{p}}$ ranged from -0.1 to $0.1 \mu$ mole $\mathrm{m}^{-2} \mathrm{~s}^{-1}$ only (see Fig. 7e). In addition, the root-mean-square errors (RMSEs) of the assimilated flux members were analysed. As shown in Fig. 8, the monthly mean RMSE was less than $0.5 \mu$ mole $\mathrm{m}^{-2} \mathrm{~s}^{-1}$ in most of the model domain, except in areas near to large cities such as Beijing, Shanghai and Guangzhou, indicating that the assimilated $\mathrm{CO}_{2}$ fluxes were reliable.

In order to evaluate the ability of CFI-CMAQ to optimize the surface $\mathrm{CO}_{2}$ fluxes comprehensively, the ratios of the monthly mean $\mathbf{F}_{t}^{*}$ to the monthly mean $\mathbf{F}_{t}^{\mathrm{p}}$ were analysed. In actual implementation, we only analysed the ratios where the absolute values of the monthly mean $\mathbf{F}_{t}^{\mathrm{p}}$ were larger than 0.1 , to avoid random noise. As shown in Fig. 9a, the ratios of the monthly mean $\mathbf{F}_{t}^{*}$ to the monthly mean $\mathbf{F}_{t}^{\mathrm{p}}$ are about 1.8 in most of China, except in the Qinghai-Tibet Plateau, where the absolute values of the monthly mean $\mathbf{F}_{t}^{\mathrm{p}}$ in February were very small and were not analysed. In addition, the ratios of the monthly mean $\overline{\mathbf{F}_{t}^{\mathrm{a}}}$ to the monthly mean $\mathbf{F}_{t}^{\mathrm{p}}$ are shown in Fig. 9b. This figure demonstrates that the impact of the assimilation of $\mathrm{X}_{\mathrm{CO}_{2}}^{\mathrm{p}}$ by CFI-CMAQ on $\mathrm{CO}_{2}$ fluxes was great in the east and south of China in general, but the influence was negligible in Northeast China due to the lack of observation data.

Time series of daily mean surface $\mathrm{CO}_{2}$ fluxes extracted from $\mathbf{F}_{t}^{*}$ and $\overline{\mathbf{F}_{t}^{\mathrm{a}}}$ were also compared with that from $\mathbf{F}_{t}^{\mathrm{p}}$ at four national background stations in China and their nearest large cities, similar to the $\mathrm{CO}_{2}$ concentration assimilation. The results are shown in Fig. 10. The background time series were much larger than the artificial true time series, especially at Haerbin, Shangdianzi, Beijing, Linan and Hangzhou, which are strongly influenced by local anthropogenic $\mathrm{CO}_{2}$ emissions. After assimilating $\mathrm{X}_{\mathrm{CO}_{2}}^{\mathrm{p}}$, the assimilated time series were near to the true time series with acceptable bias, as expected, at Waliguan, Xining, Shangdianzi, Linan and Hangzhou after the 10-day spin-up period. However, the improvements at Longfengshan and Haerbin were negligible because of a lack of observations at these locations. Also, this inversion system failed to show improvements in Beijing. One of the possible reasons was that the values of the ensemble spread of $\lambda_{i, t \mid t-1}^{\mathrm{a}}$ in the Beijing area are too large (see Fig. 11c). Beijing is located in the JingJin-Ji Urban Circle, which had strong local anthropogenic $\mathrm{CO}_{2}$ emissions during January-March. So the values of the ensemble spread of $\mathbf{C}_{i, t}^{\mathrm{f}}$ in the Beijing area at model-level 1 

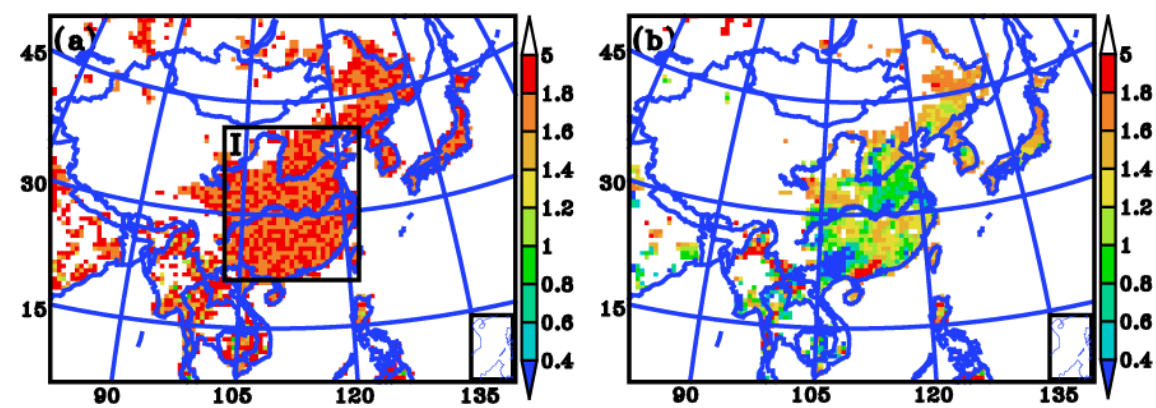

Figure 9. (a) Ratios of monthly mean $\mathbf{F}_{t}^{*}$ to monthly mean $\mathbf{F}_{t}^{\mathrm{p}}$; and (b) ratios of monthly mean $\overline{\mathbf{F}_{t}^{\mathrm{a}}}$ to monthly mean $\mathbf{F}_{t}^{\mathrm{p}}$ in February 2010 . The white part indicates the ratios where the absolute values of monthly mean $\mathbf{F}_{t}^{\mathrm{p}}$ are larger than 0.1, not analysed in this study. The black square labelled I indicates the domain where surface $\mathrm{CO}_{2}$ fluxes were used for the results presented in Figs. 12 and 13.
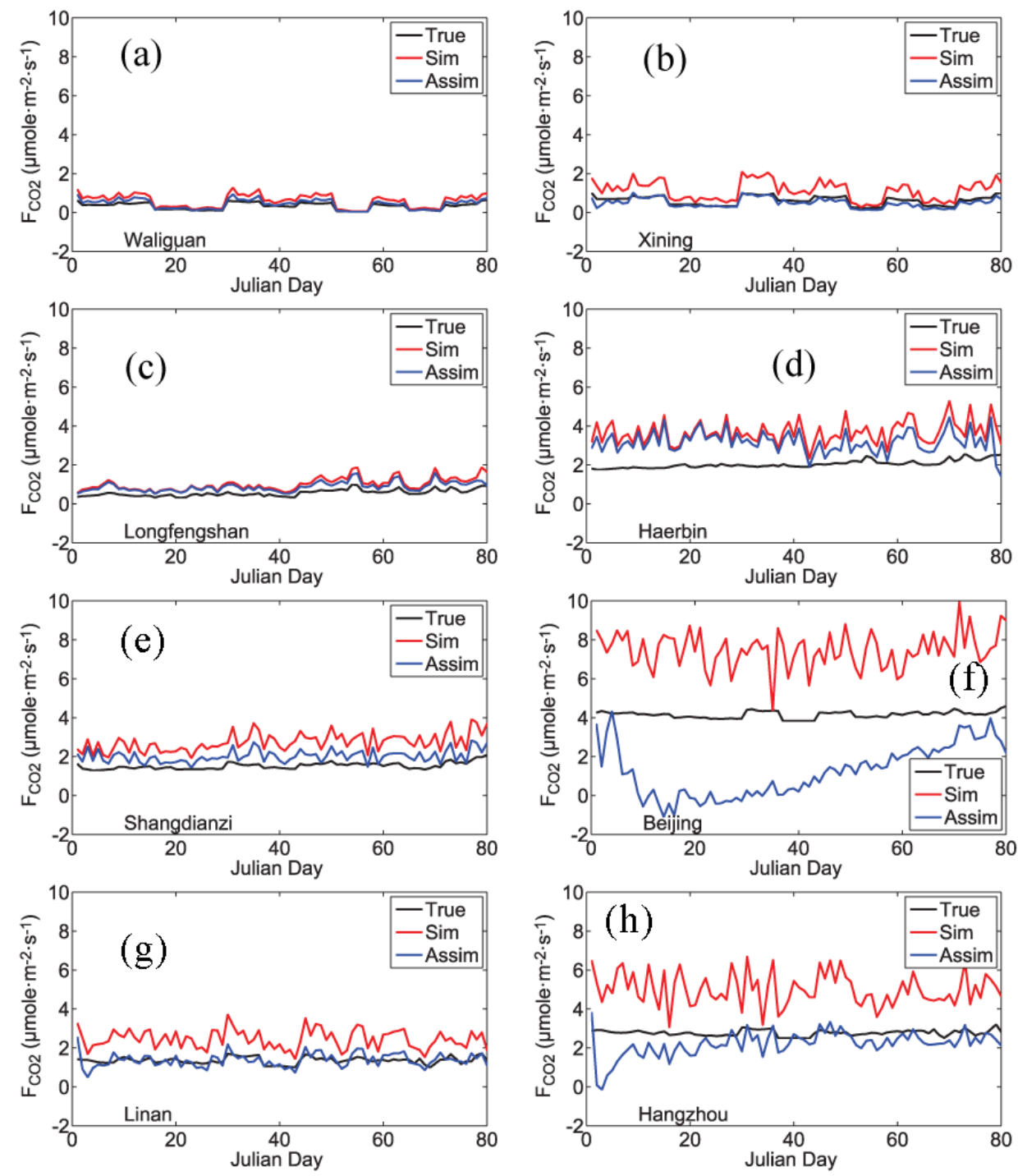

Figure 10. Daily mean time series of $\mathrm{CO}_{2}$ fluxes at national background stations in China and their nearest large cities from $1 \mathrm{January}$ to 20 March 2010, extracted from the prior true surface $\mathrm{CO}_{2}$ fluxes $\mathbf{F}_{t}^{\mathrm{p}}$ (black), the prescribed $\mathrm{CO}_{2}$ surface fluxes $\mathbf{F}_{t}^{*}$ (red), and the assimilated $\mathrm{CO}_{2}$ fluxes $\overline{\mathbf{F}_{t}^{\mathrm{a}}}$ (blue). All time series were interpolated to the observation locations by the spatial bilinear interpolator method. The sites used are (a) Waliguan, (b) Xining, (c) Longfengshan, (d) Haerbin, (e) Shangdianzi, (f) Beijing, (g) Linan, and (h) Hangzhou. 

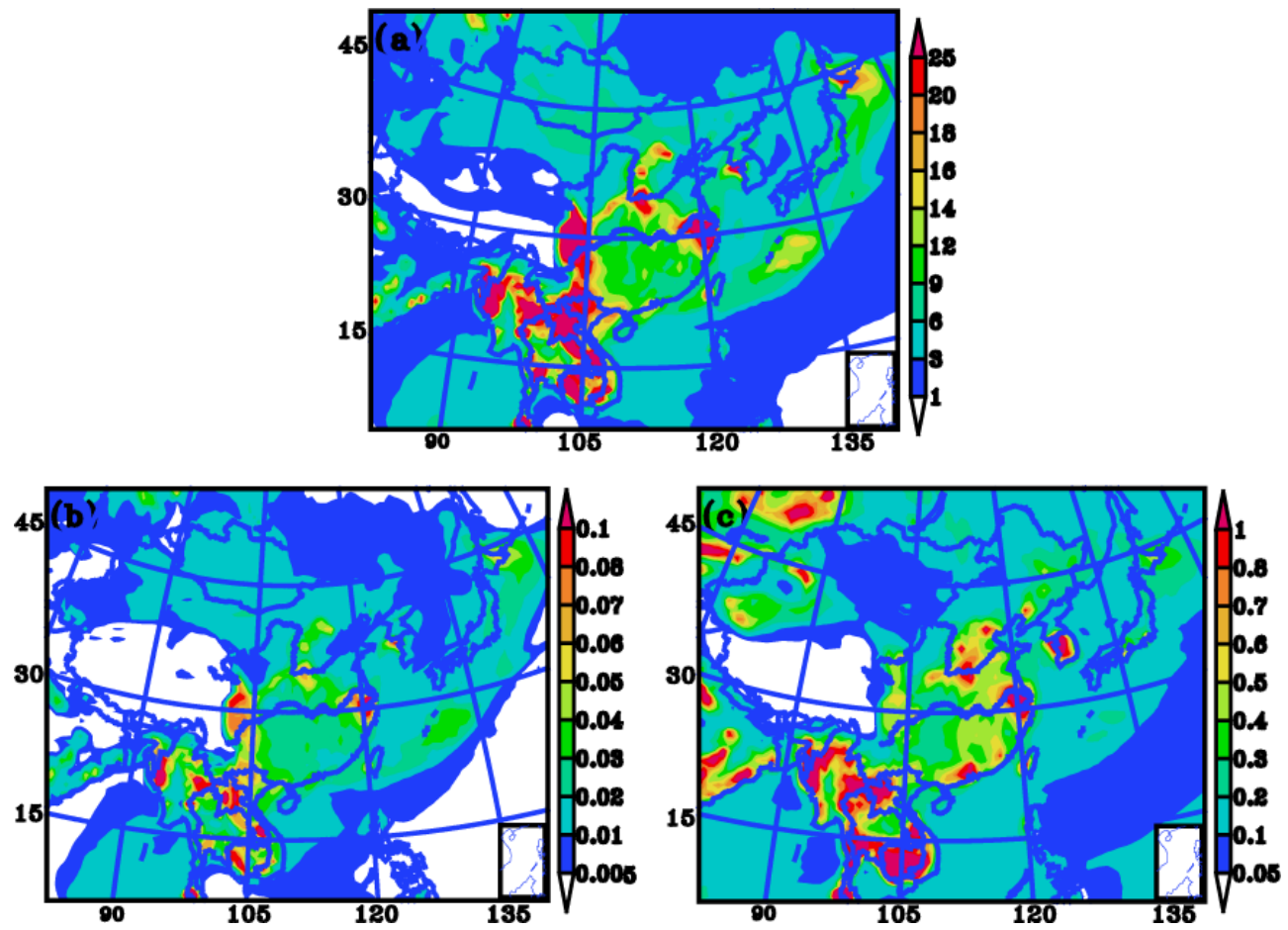

Figure 11. (a) Ensemble spread of $\mathbf{C}_{i, t}^{\mathrm{f}}$ after inflating; (b) ensemble spread of $\lambda_{i, t \mid t-1}^{\mathrm{p}}$ before inflating; (c) ensemble spread of $\lambda_{i, t \mid t-1}^{\mathrm{a}}$ at model-level 1 at 00:00 UT on 1 March 2010, when $\beta=70$.

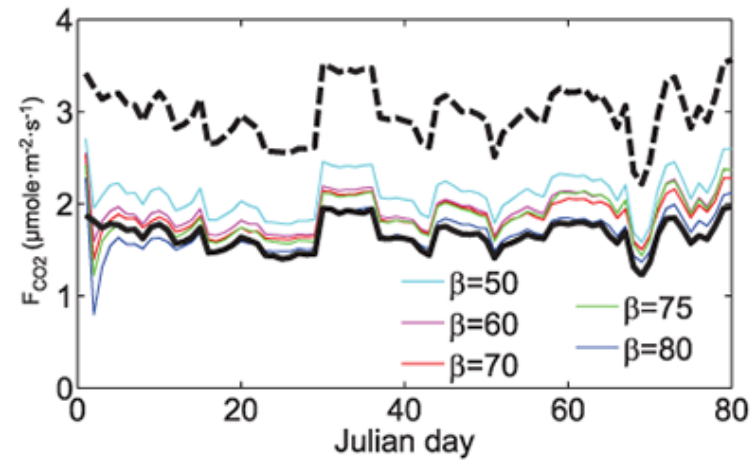

Figure 12. Time series of daily mean $\mathrm{CO}_{2}$ fluxes averaged in domain I (shown in Fig. 9a) from 1 January to 20 March 2010 with the inflation factor of scaling factors $\beta=50,60,70,75$ and 80 . The black dashed line is the time series averaged from $\mathbf{F}_{t}^{*}$ and the black solid line is the time series averaged from $\mathbf{F}_{t}^{\mathrm{p}}$.

could be much larger than those in other areas, which had weak local anthropogenic $\mathrm{CO}_{2}$ emissions (see Fig. 11a). As a result, the values of the ensemble spread of $\lambda_{i, t \mid t-1}^{\mathrm{p}}$ before inflating in the Beijing area are much larger than those in other areas with small local anthropogenic $\mathrm{CO}_{2}$ emissions (see Fig. 11b). After inflating, the ensemble spread of $\lambda_{i, t \mid t-1}^{\mathrm{p}}$ in the Beijing area could be too large, compared to those in other areas with small local anthropogenic $\mathrm{CO}_{2}$ emissions (see Fig. 11c), which led to the failure to reproduce the true fluxes in the Beijing area. Later, CFI-CMAQ will be improved by optimizing the covariance inflation method.

Since the impact of assimilation $\mathrm{X}_{\mathrm{CO}_{2}}^{\mathrm{p}}$ by CFI-CMAQ on $\mathrm{CO}_{2}$ fluxes was in general greater in the east and south of China than other model areas (see Figs. 7, 9), the time series of the daily mean $\mathrm{CO}_{2}$ fluxes in that area averaged from $\overline{\mathbf{F}_{t}^{\mathbf{a}}}$ was compared with those from $\mathbf{F}_{t}^{*}$ and $\mathbf{F}_{t}^{\mathrm{p}}$ (see Fig. 12). This figure indicates that CFI-CMAQ could in general reproduce the true fluxes with acceptable bias.

As stated in the above section, $\beta$ was a newly introduced parameter. The prior scaling factors should have been inflated indirectly through the inflated $\mathrm{CO}_{2}$ concentration forecast. However, the values of the ensemble spread of $\lambda_{i, t \mid t-1}^{\mathrm{p}}$ before inflating were very small (ranging from 0 to 0.08 in most areas at model-level 1, see Fig. 11b), though the values of the ensemble spread of $\mathbf{C}_{i, t}^{\mathrm{f}}$ after inflating could reach 114 ppmv in most areas at model-level 1 (see Fig. 11a). Consequently, we had to inflate them again before using them in Eq. (2). Fig. 11c shows the distribution of the ensemble spread of $\lambda_{i, t \mid t-1}^{\mathrm{a}}$ at model-level 1 at 00:00 UT on 1 March 2010 when $\beta=70$. It shows that the values of the ensemble spread of $\lambda_{i, t \mid t-1}^{\mathrm{a}}$ ranged from 0.1 to 0.8 in most areas. In order to investigate the sensitivity of the inflation factor of the scaling factors $\beta$, a series of numerical experiments were conducted. As shown in Fig. 12, CFI-CMAQ worked rather well for $\beta=60,70,75,80$. However, if $\beta$ was much 


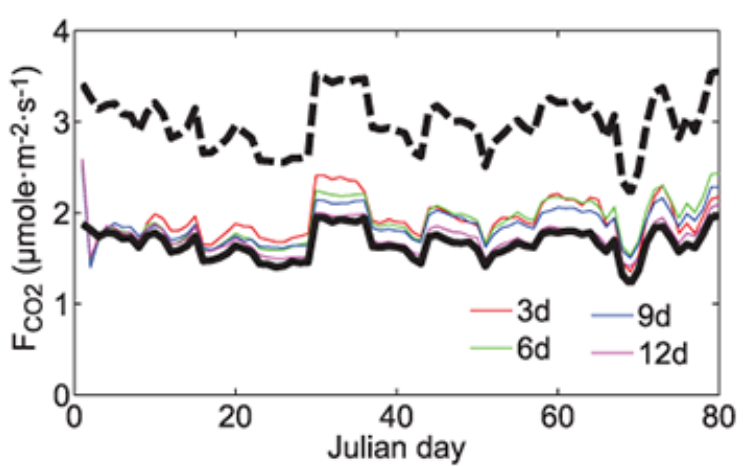

Figure 13. Time series of daily mean $\mathrm{CO}_{2}$ fluxes averaged in domain I (shown in Fig. 9a) from 1 January to 20 March 2010 with different smoother windows (3, 6, 9 and 12 days). The black dashed line is the time series averaged from $\mathbf{F}_{t}^{*}$ and the black solid line is the time series averaged from $\mathbf{F}_{t}^{\mathrm{p}}$.

smaller than 50 (e.g. $\beta=10$ ), the impact of assimilation was small due to the small ensemble spread; or if $\beta$ was much larger than 80 (e.g. $\beta=100$ ), the assimilated $\mathrm{CO}_{2}$ fluxes deviated markedly from the "true" $\mathrm{CO}_{2}$ fluxes. In other words, the performance of CFI-CMAQ greatly relies on the choice of $\beta$.

From the perspective of the lag-window, the differences among the four assimilation sensitivity experiments with lagwindows of 3, 6, 9 and 12 days were very small (see Fig. 13). Although Peters et al. (2007) indicated that the lag-window should be more than five weeks, it seemed that the smoother window had a slight influence on the assimilated results for CFI-CMAQ. It was clear that the assimilated results with a larger lag-window were better than those with a smaller lag-window; however, CFI-CMAQ performed very well even with a short lag-window (e.g. 3 days).

At the end of this subsection, the assimilation results of the reference experiment in which $\lambda_{i, t \mid t-1}^{\mathrm{p}}$ were set to 1 will be addressed briefly. The impact of assimilation $\mathrm{X}_{\mathrm{CO}_{2}}^{\mathrm{p}}$ on $\mathrm{CO}_{2}$ fluxes was disordered. The monthly mean values of the difference between the prior true surface $\mathrm{CO}_{2}$ fluxes and the ensemble mean values of the assimilated surface $\mathrm{CO}_{2}$ fluxes were irregular noise (see Fig. 14). The main reason is that all the elements of the scaling factors to be optimized in the smoother window are only random numbers. As stated in the above section, only $\lambda_{i, 1 \mid 0}^{\mathrm{a}}$ needed to be optimized in the first assimilation cycle. However, $\lambda_{i, 1 \mid 0}^{\mathrm{a}}$ were rand fields (in other words, all the elements of $\lambda_{i, 1 \mid 0}^{\mathrm{a}}$ are random numbers) because they could not be generated in other ways in the first instance. Therefore their spatial correlations were too small. The correlations between the scaling factors and the observations were also too small. It was therefore impossible to systematically change the values of $\lambda_{i, 100}^{\mathrm{a}}$ in large areas where the observations located after assimilating observations at $t=1$. Hence, the signal-to-noise problem arose. So, the elements of $\lambda_{i, 1 \mid 1}^{\mathrm{a}}$ are also only random numbers. Though $\lambda_{i, 2 \mid 1}^{\mathrm{a}}$

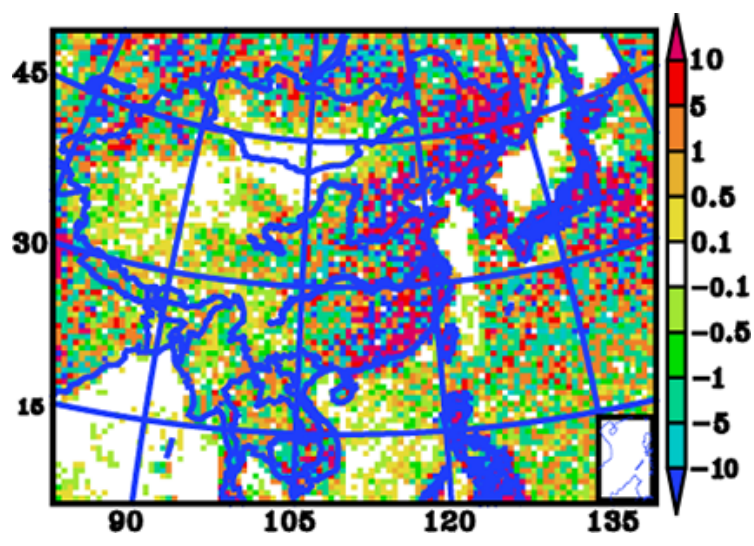

Figure 14. Monthly mean values of the difference between the prior true surface $\mathrm{CO}_{2}$ fluxes and the ensemble mean values of the assimilated surface $\mathrm{CO}_{2}$ fluxes (units: $\mu$ mole $\mathrm{m}^{-2} \mathrm{~s}^{-1}$ ) of the reference experiment in which $\lambda_{i, t \mid t-1}^{\mathrm{p}}$ were set to 1 .

could be generated automatically by the smoothing operator when all $\lambda_{i, 2 \mid 1}^{\mathrm{p}}$ were set to 1 , the elements of $\lambda_{i, 2 \mid 1}^{\mathrm{a}}$ are also random numbers because the smoothing operator is only a linear operator. Similarly, it was impossible to systematically change the values of $\lambda_{i, 1 \mid 1}^{\mathrm{a}}$ and $\lambda_{i, 2 \mid 1}^{\mathrm{a}}$ in large areas after assimilating observations at $t=2$. As this inversion system continued assimilating observations, all future scaling factors could be created by the smoothing operator and then updated. But this inversion system could not ingest the observations effectively because all the elements of the scaling factors were always random numbers. Though the 9-day lagwindow in the reference experiment is too short compared to the 5 week lag-window recommended by Peters et al. (2007), this reference experiment could illustrate the limitation by only using the smoothing operator as the persistence dynamical model. If the lag-window was around 5 weeks, we could achieve better results because there were more observations in every assimilation cycle. However, the results could not be better than those obtained by CFI-CMAQ because most grids have no observations (see Fig. 3a) and the signal-tonoise problem still remained.

\section{Summary and conclusions}

A regional surface $\mathrm{CO}_{2}$ flux inversion system, CFI-CMAQ, has been developed to optimize $\mathrm{CO}_{2}$ fluxes at grid scales. It operates under a joint data assimilation framework by applying EnKF to constrain the $\mathrm{CO}_{2}$ concentrations and applying EnKS to optimize the surface $\mathrm{CO}_{2}$ flux, which is similar to Kang et al. $(2011,2012)$ and Tian et al. (2014). The persistence dynamical model, which was first introduced by Peters et al. (2007) by applying the smoothing operator to transport the useful observed information onto the next assimilation cycle, is developed further. We associated the smoothing operator with the atmospheric transport model to con- 
stitute the persistence dynamical model to forecast the surface $\mathrm{CO}_{2}$ flux scaling factors for the purpose of resolving the "signal-to-noise" problem, as well as transporting the useful observed information onto the next assimilation cycle. In this application, the scaling factors to be optimized in the flux inversion system can be forecast at the grid scale without random noise. The OSSEs showed that the performance of CFI-CMAQ is effective and promising. In general, it could reproduce the true fluxes at the grid scale with acceptable bias.

This study represents the first step in developing a regional surface $\mathrm{CO}_{2}$ flux inversion system to optimize $\mathrm{CO}_{2}$ fluxes over East Asia, particularly over China. In future, we intend to further develop the covariance localization techniques and inflation techniques to improve the performance of CFICMAQ. Furthermore, the uncertainty of the boundary conditions should be considered to improve the effectiveness of regional $\mathrm{CO}_{2}$ flux optimization.

Acknowledgements. This work was supported by the National Natural Science Foundation of China (grant no. 41130528), the Strategic Priority Research Program - Climate Change: Carbon Budget and Relevant Issues (XDA05040404), and the National High Technology Research and Development Program of China (2013AA122002). CarbonTracker results used to generate the initial condition were provided by NOAA ESRL, Boulder, Colorado, USA from the website http://carbontracker.noaa.gov. The numerical calculations in this paper were done on the IBM Blade cluster system in the High Performance Computing Center (HPCC) of Nanjing University.

Edited by: X. Liu

\section{References}

Ahmadov, R., Gerbig, C., Kretschmer, R., Körner, S., Rödenbeck, C., Bousquet, P., and Ramonet, M.: Comparing high resolution WRF-VPRM simulations and two global $\mathrm{CO}_{2}$ transport models with coastal tower measurements of $\mathrm{CO}_{2}$, Biogeosciences, 6, 807-817, doi:10.5194/bg-6-807-2009, 2009.

Andres, R. J., Boden, T. A., Bréon, F.-M., Ciais, P., Davis, S., Erickson, D., Gregg, J. S., Jacobson, A., Marland, G., Miller, J., Oda, T., Olivier, J. G. J., Raupach, M. R., Rayner, P., and Treanton, K.: A synthesis of carbon dioxide emissions from fossil-fuel combustion, Biogeosciences, 9, 1845-1871, doi:10.5194/bg-9-18452012, 2012.

Baker, D. F., Doney, S. C., and Schimel, D. S.: Variational data assimilation for atmospheric $\mathrm{CO}_{2}$, Tellus B, 58, 359-365, 2006.

Boden, T. A., Marland, G., and Andres, R. J.: Global, regional, and national fossil-fuel $\mathrm{CO}_{2}$ emissions, Carbon Dioxide Information Analysis Center, Oak Ridge National Laboratory, US Department of Energy, Oak Ridge, Tenn., USA, doi:10.3334/CDIAC/00001_V2011, 2011.

Chevallier, F.: Impact of correlated observation errors on inverted $\mathrm{CO}_{2}$ surface fluxes from OCO measurements, Geophys. Res. Lett., 34, L24804, doi:10.1029/2007GL030463, 2007.
Chevallier, F. M. F., Peylin, P., Bousquet, S. S. P., Bréon, F.-M., Chédin, A., and Ciais, P.: Inferring $\mathrm{CO}_{2}$ sources and sinks from satellite observations: Method and application to TOVS data, J. Geophys. Res., 110, D24309, doi:10.1029/2005JD006390, 2005.

Chevallier, F., Bréon, F.-M., and Rayner, P. J.: Contribution of the Orbiting Carbon Observatory to the estimation of $\mathrm{CO}_{2}$ sources and sinks: Theoretical study in a variational data assimilation framework, J. Geophys. Res., 112, D09307, doi:10.1029/2006JD007375, 2007.

Connor, B. J., Bösch, H., Toon, G., Sen, B., Miller, C., and Crisp, D.: Orbiting Carbon Observatory: Inverse method and prospective error analysis, J. Geophys. Res., 113, D05305, doi:10.1029/2006JD008336, 2008.

Crisp, D., Bösch, H., Brown, L., Castano, R., Christi, M., Connor, B., Frankenberg, C., McDuffie, J., Miller, C. E., Natraj, V., O’Dell, C., O’Brien, D., Polonsky, I., Oyafuso, F., Thompson, D., Toon, G., and Spurr, R.: OCO (Orbiting Carbon Observatory)2 Level 2 Full Physics Retrieval Algorithm Theoretical Basis, Tech. Rep. OCO D-65488, NASA Jet Propulsion Laboratory, California Institute of Technology, Pasadena, CA, version 1.0 Rev 4, http://disc.sci.gsfc.nasa.gov/acdisc/documentation/ OCO-2_L2_FP_ATBD_v1_rev4_Nov10.pdf, (last access: 4 August 2014), 2010.

Crisp, D., Fisher, B. M., O’Dell, C., Frankenberg, C., Basilio, R., Bösch, H., Brown, L. R., Castano, R., Connor, B., Deutscher, N. M., Eldering, A., Griffith, D., Gunson, M., Kuze, A., Mandrake, L., McDuffie, J., Messerschmidt, J., Miller, C. E., Morino, I., Natraj, V., Notholt, J., O’Brien, D. M., Oyafuso, F., Polonsky, I., Robinson, J., Salawitch, R., Sherlock, V., Smyth, M., Suto, H., Taylor, T. E., Thompson, D. R., Wennberg, P. O., Wunch, D., and Yung, Y. L.: The ACOS $\mathrm{CO}_{2}$ retrieval algorithm - Part II: Global $\mathrm{X}_{\mathrm{CO}_{2}}$ data characterization, Atmos. Meas. Tech., 5, 687707, doi:10.5194/amt-5-687-2012, 2012.

Deng, F., Chen, J. M., Ishizawa, M., YUEN, C. W. A. I., Mo, G., Higuchi, K., Chan, D., and Maksyutov, S.: Global monthly $\mathrm{CO}_{2}$ flux inversion with a focus over North America, Tellus B, 59, 179-190, 2007.

Engelen, R. J., Serrar, S., and Chevallier, F.: Four-dimensional data assimilation of atmospheric $\mathrm{CO}_{2}$ using AIRS observations, J. Geophys. Res., 114, D03303, doi:10.1029/2008JD010739, 2009.

Feng, L., Palmer, P. I., Bösch, H., and Dance, S.: Estimating surface $\mathrm{CO}_{2}$ fluxes from space-borne $\mathrm{CO}_{2}$ dry air mole fraction observations using an ensemble Kalman Filter, Atmos. Chem. Phys., 9, 2619-2633, doi:10.5194/acp-9-2619-2009, 2009.

Feng, L., Palmer, P. I., Yang, Y., Yantosca, R. M., Kawa, S. R., Paris, J.-D., Matsueda, H., and Machida, T.: Evaluating a 3-D transport model of atmospheric $\mathrm{CO}_{2}$ using ground-based, aircraft, and space-borne data, Atmos. Chem. Phys., 11, 27892803, doi:10.5194/acp-11-2789-2011, 2011.

Gurney, K. R., Law, R. L., Denning, A. S., Rayner, P. J., Baker, D., Bousquet, P., Bruhwiler, L., Chen, Y. H, Ciais, P., Fan, S., Fung, I. Y., Gloor, M., Heimann, M., Higuchi, K., John, J, Maki, T., Maksyutov, S., Masarie, K., Peylin, P., Prather, M., Pak, B. C., Randerson, J., Sarmiento, J., Taguchi, S., Takahashi, T., Yuen, C. W.: Towards robust regional estimates of $\mathrm{CO}_{2}$ sources and sinks using atmospheric transport models, Nature, 415, 626-630, 2002.

Gurney, K. R., Mendoza, D. L., Zhou, Y. Y., Fischer, M. L., Miller, C. C., Geethakumar, S. and Du Can, S. D.: High resolution fos- 
sil fuel combustion $\mathrm{CO}_{2}$ emission fluxes for the United States, Environ. Sci. Technol., 43, 5535-5541. doi:10.1021/es900806c, 2009.

Houtekamer, P. L. and Mitchell, H. L.: A sequential ensemble Kalman filter for atmospheric data assimilation, Mon. Weather Rev., 129, 123-137, 2001.

Huang, Z. K., Peng, Z., Liu, H. N., Zhang, M. G.: Development of CMAQ for East Asia $\mathrm{CO}_{2}$ data assimilation under an EnKF framework: a first result, Chinese Sci. Bull., 59, 3200-3208, doi:10.1007/s11434-014-0348-9, 2014.

Jiang, F., Wang, H. W., Chen, J. M., Zhou, L. X., Ju, W. M., Ding, A. J., Liu, L. X., and Peters, W.: Nested atmospheric inversion for the terrestrial carbon sources and sinks in China, Biogeosciences, 10, 5311-5324, doi:10.5194/bg-10-5311-2013, 2013.

Kang, J.-S., Kalnay, E., Liu, J., Fung, I., Miyoshi, T., and Ide, K.: "Variable localization" in an ensemble Kalman filter: application to the carbon cycle data assimilation, J. Geophys. Res., 116, D09110, doi:10.1029/2010JD014673, 2011.

Kang, J.-S., Kalnay, E., Miyoshi, T., Liu, J., and Fung, I.: Estimation of surface carbon fluxes with an advanced data assimilation methodology, J. Geophys. Res., 117, D24101, doi:10.1029/2012JD018259, 2012.

Kou, X., Zhang, M., Peng, Z.: Numerical Simulation of $\mathrm{CO}_{2}$ Concentrations in East Asia with RAMS-CMAQ, Atmos, Oceanic Sci. Lett., 6, 179-184, 2013.

Kretschmer, R., Gerbig, C., Karstens, U., and Koch, F.-T.: Error characterization of $\mathrm{CO}_{2}$ vertical mixing in the atmospheric transport model WRF-VPRM, Atmos. Chem. Phys., 12, 2441-2458, doi:10.5194/acp-12-2441-2012, 2012.

Liu, J., Fung, I., Kalnay, E., Kang, J.: $\mathrm{CO}_{2}$ transport uncertainties from the uncertainties in meteorological fields, Geophys. Res. Lett., 38, L12808, doi:10.1029/2011GL047213, 2011.

Liu, J., Fung, I., Kalnay, E., Kang, J.-S., Olsen, E. T., and Chen, L.: Simultaneous assimilation of AIRS $\mathrm{Xco}_{2}$ and meteorological observations in a carbon climate model with an ensemble Kalman filter, J. Geophys. Res., 117, D05309, doi:10.1029/2011JD016642, 2012.

Liu Z., Bambha, R. P., Pinto, J. P.: Toward verifying fossil fuel $\mathrm{CO}_{2}$ emissions with the Community Multi-scale Air Quality (CMAQ) model: motivation, model description and initial simulation. J. Air Waste Manage. Assoc., 64, 419-435, doi:10.1080/10962247.2013.816642, 2013.

Marland, G.: Uncertainties in accounting for $\mathrm{CO}_{2}$ from fossil fuels, J. of Indust. Ecol., 12, 136-139, doi:10.1111/j.15309290.2008.00014.x, 2008.

Miyazaki K.: Performance of a local ensemble transform Kalman filter for the analysis of atmospheric circulation and distribution of long-lived tracers under idealized conditions, J. Geophys. Res., 114, D19304, doi:10.1029/2009JD011892, 2009.

National Research Council (NRC): Verifying greenhouse gas emissions: Methods to support international climate agreements, The National Academies Press, Washington, DC, available at: http: //www.nap.edu/download.php?record_id=12883 (last access: 27 January 2015), 2010.

O’Dell, C. W., Connor, B., Bösch, H., O’Brien, D., Frankenberg, C., Castano, R., Christi, M., Eldering, D., Fisher, B., Gunson, M., McDuffie, J., Miller, C. E., Natraj, V., Oyafuso, F., Polonsky, I., Smyth, M., Taylor, T., Toon, G. C., Wennberg, P. O., and Wunch, D.: The ACOS $\mathrm{CO}_{2}$ retrieval algorithm - Part 1: Description and validation against synthetic observations, Atmos. Meas. Tech., 5, 99-121, doi:10.5194/amt-5-99-2012, 2012.

Osterman, G., Martinez, E., Eldering, A., and Avis, C.: ACOS Level 2 Standard Product Data User's Guide, v2.9, available at: http://oco.jpl.nasa.gov/files/ocov2/v2.9_DataUsersGuide_ RevD_20121026.pdf.pdf (last access: 27 January 2015), 2011.

Peters, W., Miller, J. B., Whitaker, J., Denning, A. S., Hirsch, A., Krol, M. C., Zupanski, D., Bruhwiler, L., and Tans, P. P.: An ensemble data assimilation system to estimate $\mathrm{CO}_{2}$ surface fluxes from atmospheric trace gas observations, J. Geophys. Res., 110, D24304, doi:10.1029/2005JD006157, 2005.

Peters, W., Jacobson, A. R., Sweeney, C., Andrews, A. E., Conway, T. J., Masarie, K., Miller, J. B., Bruhwiler, L. M. P., Petron, G., Hirsch, A. I., Worthy, D. E. J., van der Werf, G. R.,Randerson, J. T., Wennberg, P. O., Krol, M. C., and Tans, P. P.: An atmospheric perspective on North American carbon dioxide exchange: CarbonTracker, P. Natl. Acad. Sci. USA, 104, 18925-18930, 2007.

Peters, W., KROL, M. C., Van Der WERF, G. R., Houwling, S., Jones, C. D., Hughes, J., Schaefer, K., Masarie, K. A., Jacobson, A. R., Miller, J. B., Cho, C. H., Ramonet, M., Schmidt, M., Ciattaglia, L., Apadula, F., Heltai, D., Meinhardt, F., Di Sarra, A. G., Piachentina, S., Sferlazzo, D., Aalto, T., Hatakka, J., Ström, J., Haszpra, L., Meijer, H. A. J., Van Der Laan, S., Neubert, R. E. M., Jordan, A., Rodo, X., Morgui, J. -A., Vermeulen, A. T., Popa, E., Rozanski, M., Manning, A. C., Leuenberger, M., Uglietti, C., Dolman, A. J., Ciais, P., Heimann, M., Tans, P. P.: Seven years of recent Europenan net terrestrial carbon dioxide exchange constrained by atmisppheric observations, Glob. Change Biol., 16, 1365-2486, 2009.

Peylin, P., Law, R. M., Gurney, K. R., Chevallier, F., Jacobson, A. R., Maki, T., Niwa, Y., Patra, P. K., Peters, W., Rayner, P. J., Rödenbeck, C., van der Laan-Luijkx, I. T., and Zhang, X.: Global atmospheric carbon budget: results from an ensemble of atmospheric $\mathrm{CO}_{2}$ inversions, Biogeosciences, 10, 6699-6720, doi:10.5194/bg-10-6699-2013, 2013.

Pillai, D., Gerbig, C., Ahmadov, R., Rödenbeck, C., Kretschmer, R., Koch, T., Thompson, R., Neininger, B., and Lavrié, J. V.: High-resolution simulations of atmospheric $\mathrm{CO}_{2}$ over complex terrain - representing the Ochsenkopf mountain tall tower, Atmos. Chem. Phys., 11, 7445-7464, doi:10.5194/acp-11-74452011, 2011.

Prather, M., Zhu, X., Strahan, S.E., Steenrod, S., D., and Rodriguez, J., M.: Quantifying errors in trace species transport modeling, P. Natl. Acad. Sci. USA, 105, 19617-19621. doi:10.1073/pnas.0806541106, 2008.

Tangborn, A., Strow, L. L., Imbiriba, B., Ott, L., and Pawson, S.: Evaluation of a new middle-lower tropospheric $\mathrm{CO}_{2}$ product using data assimilation, Atmos. Chem. Phys., 13, 4487-4500, doi:10.5194/acp-13-4487-2013, 2013.

Tian, X., Xie, Z., and Sun, Q.: A POD-based ensemble fourdimensional variational assimilation method, Tellus A, 63, 805816, 2011.

Tian, X., Xie, Z., Liu, Y., Cai, Z., Fu, Y., Zhang, H., and Feng, L.: A joint data assimilation system (Tan-Tracker) to simultaneously estimate surface $\mathrm{CO} 2$ fluxes and 3-D atmospheric $\mathrm{CO}_{2}$ concentrations from observations, Atmos. Chem. Phys., 14, 1328113293, doi:10.5194/acp-14-13281-2014, 2014.

van der Werf, G. R., Randerson, J. T., Giglio, L., Collatz, G. J., Mu, M., Kasibhatla, P. S., Morton, D. C., DeFries, R. S., Jin, Y., and 
van Leeuwen, T. T.: Global fire emissions and the contribution of deforestation, savanna, forest, agricultural, and peat fires (19972009), Atmos. Chem. Phys., 10, 11707-11735, doi:10.5194/acp10-11707-2010, 2010.

Wang, B., Liu, J., Wang, S., Cheng, W., Liu, J., Liu, C., Xiao Q., and Kuo, Y.: An economical approach to four-dimensional variational data assimilation, Adv. Atmos. Sci., 27, 715-727, doi:10.1007/s00376-009-9122-3, 2010.

Zhang, H. F., B. Z. Chen, I. T. van der Laan-Luijkx, J. Chen, G. Xu, J. W. Yan, L. X. Zhou, Y. Fukuyama, P. P. Tans, and W. Peters, Net terrestrial $\mathrm{CO}_{2}$ exchange over China during 20012010 estimated with an ensemble data assimilation system for atmospheric $\mathrm{CO}_{2}$, J. Geophys. Res. Atmos., 119, 3500-3515, doi:10.1002/2013JD021297, 2014a.

Zhang, H. F., Chen, B. Z., van der Laan-Luijk, I. T., Machida, T., Matsueda, H., Sawa, Y., Fukuyama, Y., Langenfelds, R., van der Schoot, M., Xu, G., Yan, J. W., Cheng, M. L., Zhou, L. X., Tans, P. P., and Peters, W.: Estimating Asian terrestrial carbon fluxes from CONTRAIL aircraft and surface $\mathrm{CO}_{2}$ observations for the period 2006-2010, Atmos. Chem. Phys., 14, 5807-5824, doi:10.5194/acp-14-5807-2014, 2014b.
Zhang, M., Uno, I., Sugata, S., Wang, Z., Byun, D., Akimoto, H.: Numerical study of boundary layer ozone transport and photochemical production in East Asia in the wintertime, Geophys. Res. Lett., 29, 40-1-40-4, doi:10.1029/2001GL014368, 2002.

Zhang, M., Uno, I., Carmichael, G. R., Akimoto, H., Wang, Z., Tang, Y., Woo, J., Streets, D. G., Sachse, G. W., Avery, M. A., Weber, R. J., Talbot, R. W.: Large-scale structure of trace gas and aerosol distributions over the western Pacific Ocean during the Transport and Chemical Evolution Over the Pacific (TRACE-P) experiment, J. Geophys. Res., 108, 8820, doi:10.1029/2002JD002946, 2003.

Zhang, M., Gao, L., Ge, C., Xu, Y.: Simulation of nitrate aerosol concentrations over East Asia with the model system RAMSCMAQ, Tellus B, 59, 372-380, 2007. 